\title{
Nonsynaptic NMDA Receptors Mediate Activity-Dependent Plasticity of Gap Junctional Coupling in the AII Amacrine Cell Network
}

\author{
W. Wade Kothmann, ${ }^{1,2}$ E. Brady Trexler, ${ }^{3}$ Christopher M. Whitaker, ${ }^{1}$ Wei Li, ${ }^{4}$ Stephen C. Massey, ${ }^{1,2}$ and John 0 'Brien ${ }^{1,2}$ \\ ${ }^{1}$ Richard S. Ruiz Department of Ophthalmology and Visual Science, University of Texas Medical School, Houston, Texas 77030, ${ }^{2}$ University of Texas \\ Graduate School of Biomedical Sciences at Houston, Houston, Texas 77030, ${ }^{3}$ Departments of Ophthalmology and Neuroscience, Mount Sinai School of \\ Medicine, New York, New York 10029, and ${ }^{4}$ Unit on Retinal Neurophysiology, National Eye Institute, Bethesda, Maryland 20892-3739
}

\begin{abstract}
Many neurons are coupled by electrical synapses into networks that have emergent properties. In the retina, coupling in these networks is dynamically regulated by changes in background illumination, optimizing signal integration for the visual environment. However, the mechanisms that control this plasticity are poorly understood. We have investigated these mechanisms in the rabbit AII amacrine cell, a multifunctional retinal neuron that forms an electrically coupled network via connexin 36 (Cx36) gap junctions. We find that presynaptic activity of glutamatergic $\mathrm{ON}$ bipolar cells drives increased phosphorylation of $\mathrm{Cx} 36$, indicative of increased coupling in the AII network. The phosphorylation is dependent on activation of nonsynaptic NMDA receptors that colocalize with Cx36 on AII amacrine cells, and is mediated by CaMKII. This activity-dependent increase in Cx36 phosphorylation works in opposition to dopamine-driven reduction of phosphorylation, establishing a local dynamic regulatory mechanism, and accounting for the nonlinear control of AII coupling by background illumination.
\end{abstract}

\section{Introduction}

One requirement for sensory systems is the ability to adapt to fluctuations in prevailing environmental conditions. For instance, in the course of $1 \mathrm{~d}$ the retina must maintain its ability to reliably encode the visual environment and transmit this code to the brain, despite the fact that the mean level of background luminance will shift $>10^{9}$-fold from night to day (Rodieck, 1998; Rieke and Rudd, 2009). Adaptation serves to maintain the appropriate dynamic range of signaling, preventing saturation yet preserving discrimination of relevant differences, thus optimizing sensory system function. A hallmark of luminance adaptation in the retina is modulation of the strength of electrical coupling among horizontal and amacrine cell interneuron networks (Bloomfield et al., 1997; Xin and Bloomfield, 1999; Bloomfield and Völgyi, 2004). Modulation of coupling strength in these networks alters receptive field size, and consequently changes the spatial extent of feedback and feedforward inhibition. In the AII amacrine cell interneuron network, electrical coupling also improves the signal-to-noise ratio

Received Oct. 7, 2011; revised Feb. 28, 2012; accepted March 19, 2012.

Author contributions: W.W.K., E.B.T., W.L., S.C.M., and J.O. designed research; W.W.K., E.B.T., C.M.W., and W.L. performed research; W.W.K., E.B.T., W.L., and J.0. analyzed data; W.W.K. and J.0. wrote the paper.

This research was supported by an NRSA fellowship to W.W.K. (NS63534), NIH awards to J.O. (EY12857), E.B.T. (EY16392), and S.C.M. (EY06515), an NIH core grant (EY10608), and a Research to Prevent Blindness grant to the Department of Ophthalmology and Visual Science. We are grateful to R. Heidelberger, S. Mills, and J. Diamond for insightful discussions on this work, and $\mathrm{H}$. Wässle for a prescient suggestion.

The authors declare no competing financial interests.

Correspondence should be addressed to W. Wade Kothmann at his present address: Synaptic Physiology Section, National Institute of Neurological Disorders and Stroke, 35 Convent Drive, Bethesda, MD 20892-3701. E-mail: Wade.Kothmann@gmail.com.

DOI:10.1523/JNEUROSCI.5087-11.2012

Copyright $\odot 2012$ the authors $\quad 0270-6474 / 12 / 326747-13 \$ 15.00 / 0$ of the light response under scotopic conditions (Vardi and Smith, 1996; Dunn et al., 2006).

The AII amacrine cell is an obligatory component of the high-sensitivity rod photoreceptor pathway (Güldenagel et al., 2001; Deans et al., 2002; Völgyi et al., 2004), and is extensively coupled to neighboring AIIs by connexin 36 (Cx36) gap junctions (Kolb and Famiglietti, 1974; Famiglietti and Kolb, 1975; Vaney, 1991; Feigenspan et al., 2001; Mills et al., 2001; Veruki and Hartveit, 2002). AII amacrine cells display a nonlinear, inverted U-shaped pattern of electrical and tracer coupling relative to increasing background illumination (Bloomfield et al., 1997; Bloomfield and Völgyi, 2004). In well dark-adapted retina (no adapting background illumination), the AII network is relatively uncoupled. When the retina is adapted to background illumination in the rod photoreceptor-dominated (scotopic) range of vision, AII amacrine cell coupling strengthens dramatically. Coupling strengthens modestly with increases in illumination through the scotopic range of vision, but as background illumination is increased further, nearing the cone photoreceptordominated (photopic) range of vision, coupling is reduced toward baseline levels. This reduction of coupling is thought to occur through increased dopamine signaling in daytime, lightadapted retina (Hampson et al., 1992; Witkovsky, 2004). Recent work has demonstrated a direct relationship between the phosphorylation state of $\mathrm{Cx} 36$ and tracer coupling in the AII network, and shown that dephosphorylation of the protein mediates the uncoupling caused by dopamine signaling (Kothmann et al., 2009). However, given that dopamine release increases steadily with increasing background illumination (Mills et al., 2007), dopamine signaling alone cannot account for inverted U-shaped 
AII coupling-background light relationship. The mechanism responsible for increasing coupling in the AII network in the lower end of the rod-dominated visual range is still unclear.

The observation that AII amacrine cell coupling strengthens with background illumination suggests an activity-dependent process driven by the ON pathways in retinal circuitry. AII amacrine cells express functional NMDA receptors (Hartveit and Veruki, 1997; Zhou and Dacheux, 2004), which commonly mediate activity-dependent changes in postsynaptic neurons. However, the major glutamatergic synaptic input to AIIs is from rod bipolar cells and is mediated entirely by AMPA receptors (Singer and Diamond, 2003; Veruki et al., 2003; Trexler et al., 2005). At present, no study has described a physiological role for the NMDA receptors on AIIs. In this study, we sought to identify the mechanism that potentiates Cx36-mediated coupling, finding a direct role for nonsynaptic NMDA receptors in the process.

\section{Materials and Methods}

Intracellular injections. Intracellular injections were made as described previously in detail (Kothmann et al., 2009). Briefly, 3.5\% Neurobiotin (Vector Laboratories) was injected by iontophoresis $( \pm 1 \mathrm{nA}, 3 \mathrm{~Hz})$ into AII amacrine cells for $5 \mathrm{~min}$, after which the tracer was allowed to diffuse for $15 \mathrm{~min}$. Each piece of retina was superfused with oxygenated Ames medium (warmed to $35^{\circ} \mathrm{C}$ ) throughout the injection and diffusion periods. For pieces that were superfused with Ames supplemented with $(R S)$ 3-(2-carboxypiperazin-4-yl)-propyl-1-phosphonic acid (CPP), treatment began 15 min before the start of the injection. Following the diffusion period the retina was then fixed in $4 \%$ formaldehyde in $0.1 \mathrm{~m}$ phosphate buffer for $15 \mathrm{~min}$ and subsequently processed for imaging.

Pharmacology experiments. Retina-sclera preparations were made from rabbits of either sex, and pharmacology experiments were performed as described previously (Kothmann et al., 2009), except as described below. For dark-adapted experiments, the whole superior portion of the eyecup was stored in Ames medium continuously bubbled with $95 \% \mathrm{O}_{2} / 5 \% \mathrm{CO}_{2}$ at room temperature inside a light-tight chamber for a minimum of $100 \mathrm{~min}$. The light-tight chamber was then kept in a dark room for the duration of the adaptation period. After the adaptation period, the superior portion of the eyecup was cut into four or six pieces as described previously (Kothmann et al., 2009), except that this was performed under infrared illumination. Once separated, the pieces were incubated with pharmacologic agents in continuously bubbled Ames inside the light-tight chamber. Light-adapted experiments were done under fluorescent white room lights, with a flux of $22.9 \times 10^{4}$ photons $\mu \mathrm{m}^{-2} \mathrm{~s}^{-1}$ measured at the location where tissue was incubated with treatment conditions. All drugs were purchased from Tocris Bioscience.

Immunolabeling. Immunolabeling for calretinin, Cx36, and phosphoSer293-Cx36 was performed as described previously (Kothmann et al., 2009). Additional antibodies used were rabbit anti-NR1 (1:100 dilution; Millipore Bioscience Research Reagents), rabbit anti-phospho-Thr286CaMKII (1:1000 dilution; PhosphoSolutions), and mouse monoclonal antibodies against PKC $\alpha$ (1:500 dilution; Transduction Laboratories) and kinesin II (1:100 dilution, Covance).

Imaging and data quantification. Images presented in Figures 2 and 3 (see below) were acquired on a Zeiss LSM-410 confocal microscope with a $63 \times$ objective [1.4 numerical aperture (N.A.)]. Alignment for all three channels was checked at $8 \times$ zoom using $1 \mu \mathrm{m}$ fluorescent beads (Invitrogen). The point spread function was measured in $x y$ as $\sim 300 \mathrm{~nm}$ using subresolution, $0.1 \mu \mathrm{m}$ fluorescent beads. The average distribution of synaptic structures around NMDAR clusters was obtained by clipping $2 \mu \mathrm{m}$ square sections of the image centered on NMDARs, aligning these frames, and signal averaging for all three channels. Results were displayed as surface plots using custom software. This is a method to analyze the average distribution of labeling in the other two channels around a repeated neuronal structure (Mills et al., 2001; Li et al., 2002). In the present study, it was used as a method to assess the average distribution of synaptic ribbons, rod bipolar terminals, and Cx36 plaques around NMDAR clusters.

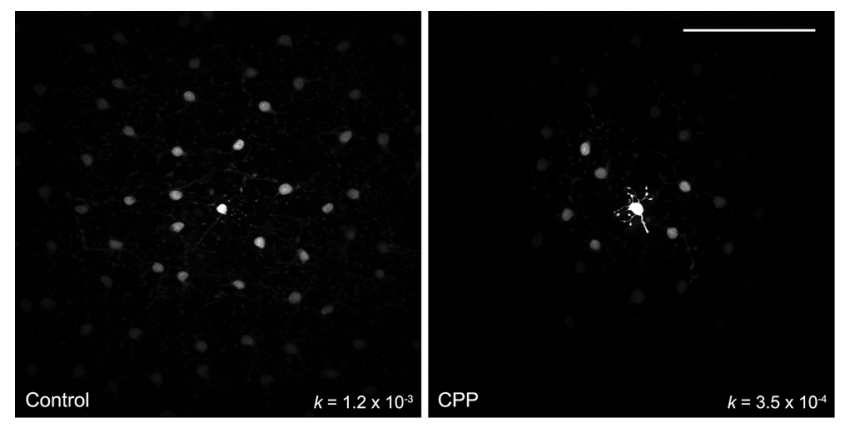

Figure 1. Blockade of NMDA receptors reduces tracer coupling between All amacrine cells. A Neurobiotin tracer coupling between All amacrine cells in light-adapted retina (control, left) is greatly reduced by blockade of NMDA receptors (CPP, $10 \mu \mathrm{m}$, right). Diffusion coefficients listed are for the All networks presented. Mean diffusion coefficients were as follows: control, $0.0012 \pm 0.00018$ cells $^{2} / \mathrm{s}(n=7) ;$ vs (PP, $0.00036 \pm 0.000028$ cells $^{2} / \mathrm{s}(n=6)$; unpaired $t$ test $p=0.0033$. Images presented are 3- $\mu \mathrm{m}$-deep $z$-stacks. Scale bar, $100 \mu \mathrm{m}$.

All other confocal images were collected on a Zeiss LSM 510 Meta confocal microscope using a $63 \times(1.4$ N.A.) objective (pharmacology experiments) or a $40 \times$ (1.3 N.A.) objective (coupling experiments). Imaging settings in the LSM software were identical where comparisons are made. Coupling between AII amacrine cells was quantified as the diffusion coefficient of the Neurobiotin tracer, which was calculated by fitting the fluorescence intensity of AII somas and distance from the injected cell to a 2-dimensional compartmental diffusion model (Xia and Mills, 2004). Cx36 phosphorylation was quantified as the ratio of the mean intensity of Ser293-P to mCx36 immunofluorescence at individual ROIs, each identified by the $\mathrm{mCx} 36$ label as a single $\mathrm{Cx} 36$ gap junction plaque. ROI identification was performed as described previously (Kothmann et al., 2009).

A minimum of four images were collected at mid-peripheral eccentricity from each condition in the pharmacology experiments. The ratio of the mean intensity of Ser293-P to mCx36 immunofluorescence was calculated for each ROI and averaged across all ROIs in all images per condition. In this way, we collapsed the phosphorylation data into one value per condition per animal to perform statistical analysis.

Images presented in the figures were collected using identical settings in the LSM software. Processing was limited to application of a $10 \%$ intensity threshold in all channels to minimize background noise.

Statistical analysis. An unpaired, two-tailed $t$ test was used to compare diffusion coefficients from the tracer injection experiments. Pharmacology experiments were analyzed with one-way repeated-measures ANOVA tests. If a significant difference between the means was found, all conditions were then compared with the control condition with Bonferroni's multiple-comparison test. Conditions that shared a common drug (e.g., CPP vs NBQX + CPP in Fig. 4; see below) were also included in the Bonferroni's test.

\section{Results}

NMDA receptor activation drives increased coupling between AII amacrine cells

Although much work has been done to characterize the glutamatedriven ionic currents present in AII amacrine cells (Hartveit and Veruki, 1997; Mørkve et al., 2002; Veruki et al., 2003; Zhou and Dacheux, 2004), it remains unclear what function is performed by NMDA receptors expressed by these cells. Since the increase in AII amacrine cell coupling in the scotopic range of vision has the appearance of an activity-dependent process, we tested the effects of NMDA receptor blockade on tracer coupling between AII amacrine cells. We made iontophoretic injections of the Cx36-permeant tracer Neurobiotin into AII amacrine cells in isolated, light-adapted retina in control Ames medium or Ames supplemented with the NMDA receptor antagonist CPP $(10 \mu \mathrm{M})$. Blockade of NMDA receptors reduced tracer coupling by $70 \%$ (Fig. 1, diffusion coefficients 

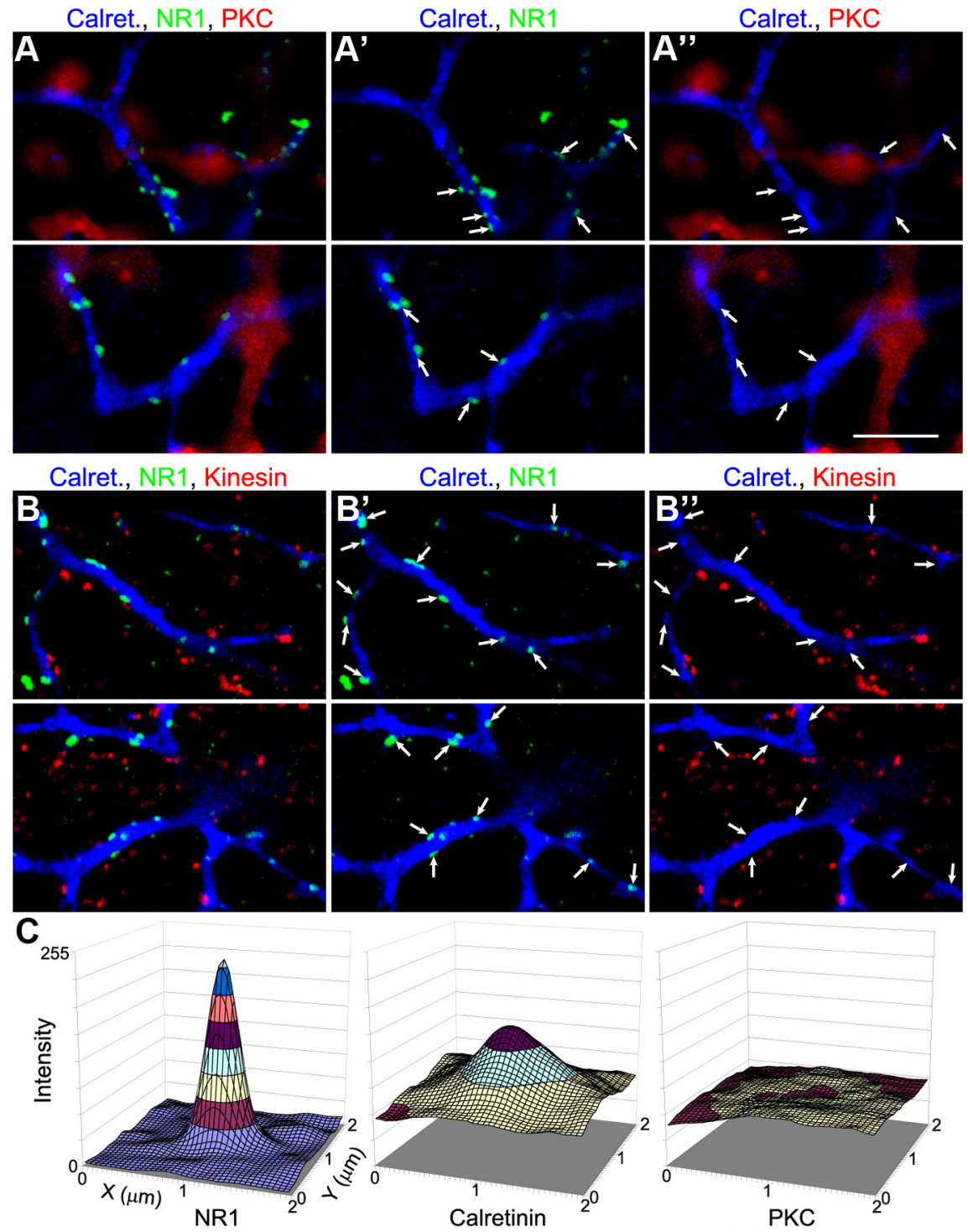

$D_{255}$
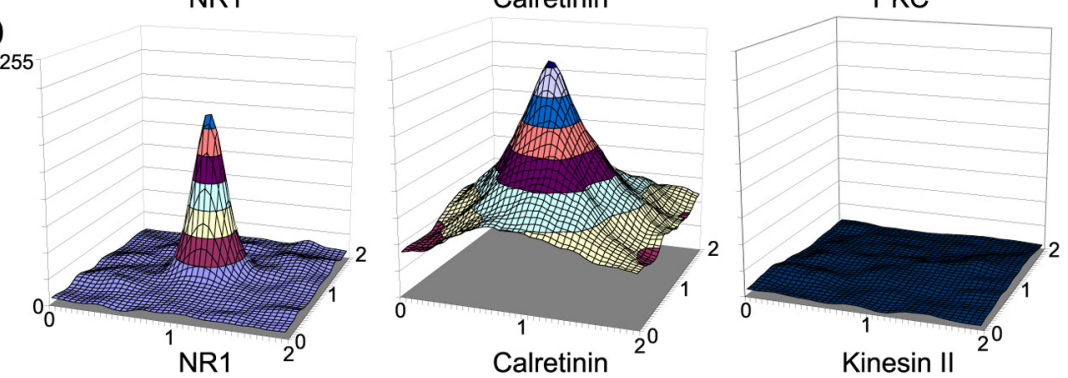

Figure 2. NMDA receptors on All amacrine cells are nonsynaptic. $\boldsymbol{A}$, Two high-magnification images show the location of NMDA receptors, labeled by antibodies against the NR1 subunit (green), on All amacrine cell dendrites, labeled by calretinin antibodies (blue), as well as presynaptic rod bipolar cell terminals, labeled by antibodies against PKC $\alpha$ (red) $\boldsymbol{A}^{\prime}$, Arrows indicate the locations of several NR1 puncta associated with All dendrites. $\mathbf{A}^{\prime \prime}$, The arrows indicating the positions of the NR1 puncta show that NMDA receptors on Alls are not associated with rod bipolar cell inputs to the All dendrites. Scale bar, $5 \mu \mathrm{m}$. $\boldsymbol{B}$, As described in $\boldsymbol{A}$, but with kinesin Il antibodies (red), which label synaptic ribbons in bipolar cell terminals, substituted for PKC $\alpha$. $\boldsymbol{B}^{\prime}$, As described in $\boldsymbol{A}^{\prime}$. $\boldsymbol{B}^{\prime \prime}$, The arrows indicating the positions of the NR1 puncta show that NMDA receptors on Alls are not associated with sites of glutamate release. For contrast, compare with the association of kinesin II labeling and AMPA receptors on All dendrites (Li et al., 2002). C, Analysis of the average fluorescent signals spatially associated with 103 NR1 puncta on All dendrites. The flatness of the PKC plot indicates that rod bipolar terminals were not spatially associated with the sites of NMDA receptors on All amacrine cells. D, As in $C$, but for 77 NR1 puncta on All dendrites and kinesin II. The flatness of the kinesin II plot indicates that presynaptic ribbons were not spatially associated with the sites of NMDA receptors on All amacrine cells. (mean $\pm \mathrm{SD}):$ control $0.0012 \pm 0.00018$ cells $^{2} / \mathrm{s}, n=7$, vs CPP $0.00036 \pm 0.000028$ cells ${ }^{2} / s, n=6$; unpaired $t$ test, $p=0.0033$ ), demonstrating that NMDA receptor activation is critical for maintaining coupling between AII amacrine cells.

There is no evidence for functional NMDA receptors in the rod pathway upstream of AII amacrine cells; thus, the most likely site of action for CPP is the NMDA receptors on AIIs. Although exogenous application of agonist activates NMDA receptors on AIIs (Hartveit and Veruki, 1997; Zhou and Dacheux, 2004), both spontaneous and rod bipolar cell-evoked EPSCs in AII amacrine cells are mediated solely by AMPA receptors (Singer and Diamond, 2003; Veruki et al., 2003; Trexler et al., 2005), suggesting that NMDA receptors on AIIs are likely extrasynaptic. To understand how NMDA receptors influence AII amacrine cell coupling, we used immunochemistry to investigate their anatomical location.

\section{NMDA receptors on AII amacrine cells are nonsynaptic}

Whole mount retinas were labeled with polyclonal antibodies against the NR1 subunit, and AII amacrine cells were labeled diffusely with antibodies against the $\mathrm{Ca}^{2+}$-binding protein calretinin (Massey and Mills, 1999). Finally, we included antibodies against PKC $\alpha$ or kinesin II to label rod bipolar cells or all synaptic ribbons in nearby ON-type bipolar cells, respectively (Li et al., 2002). NR1 labeling was localized on the fine dendrites of AII amacrine cells in sublamina $b$ of the inner plexiform layer (IPL) (Fig. 2A,B). AIIs were nearly devoid of NR1 labeling in sublamina a, where their lobular dendrites ramify (data not shown). Arrows in Figure 2 were placed to indicate the location of NR1 labeling associated with AII amacrine cell dendrites. Examination of rod bipolar cell labeling (Fig. $2 \mathrm{~A}$ ) showed that most NMDA receptors on the AII dendrites are not closely apposed to rod bipolar cell terminals. Further investigation of the synaptic ribbon labeling (Fig. $2 B$ ) revealed that most NMDA receptors on AIIs were not closely apposed to sites of glutamate release from any nearby ON-type bipolar cells. Since the kinesin II antibodies label synaptic ribbons in both rod and cone bipolar cells, it appears that the NMDA receptors on AIIs do not receive any direct glutamatergic input. This interpretation is reinforced when contrasted against a similar immunolabeling experiment that demonstrated that AMPA receptors on AIIs are only found at contacts with rod bipolar cell terminals, where they 
are closely associated with kinesin II-labeled ribbons in the rod bipolar cell terminals (Li et al., 2002).

To analyze the relationship between NR1 puncta and rod bipolar cell terminals or synaptic ribbons, square sampling boxes ( $2 \mu \mathrm{m}$ per side) were placed centered on NR1 puncta located on AII dendrites (see Materials and Methods). The spatial intensity distributions of fluorescence for each antibody was calculated and then averaged across all sampling boxes (Fig. 2C,D). The flatness of the PKC and kinesin II channel averages indicates that there was no regular relationship between NR1 labeling on AII dendrites and presynaptic rod bipolar cells or glutamate release sites in nearby bipolar cells. Additionally, we measured the nearest neighbor distance between the centers of mass of NR1-kinesin II puncta pairs, finding a mean distance $( \pm S \mathrm{SD})$ of $2.4 \pm 0.86 \mu \mathrm{m}(n=39)$. In contrast, when we performed the nearest neighbor analysis for GluR2/3-kinesin II puncta pairs (data originally published in the study by Li et al., 2002) we calculated a mean distance of $0.31 \pm 0.083 \mu \mathrm{m}(n=45)$. Furthermore, when we reanalyzed the NR1-kinesin II puncta pairs and only included kinesin II puncta that were clearly apposed to AII dendrites (putative rod bipolar ribbons), the mean nearest neighbor distance increased to $3.3 \pm 2.2 \mu \mathrm{m}$. Since kinesin II labeled-ribbons that are not closely apposed to AII dendrites identify synaptic ribbons in cone bipolar cells, these measurements indicate that NMDA receptors on AIIs are, on average, closer to sites of glutamate release from cone bipolar cells than from rod bipolar cells (nearest neighbor (all ribbons), $n=39$, vs nearest neighbor (putative rod bipolar ribbons), $n=39$; unpaired $t$ test, $p=0.027$ ). All together, our evidence shows that NMDA receptors on AII amacrine cells are true extrasynaptic or nonsynaptic receptors, as opposed to perisynaptic receptors, which are regularly positioned very near to the postsynaptic density (Zhang and Diamond, 2006). The nonsynaptic location is consistent with the absence of NMDAmediated input from rod bipolar cells in paired recordings.

\section{NMDA receptors on AII amacrine cells colocalize with Cx36 gap junctions}

Although NMDA receptors do not participate in the synaptic response of AII amacrine cells, it remains possible that glutamate spillover (Barbour and Häusser, 1997) or extracellular glutamate "tone" (Sah et al., 1989; Gottesman and Miller, 2003) might activate nonsynaptic NMDA receptors in AII amacrine cells. In particular, intermittent NMDA receptor activation by glutamate tone is likely to exert a weak influence on the membrane potential of the cell, but might still provide significant $\mathrm{Ca}^{2+}$ influx in local domains. Both NMDA receptor activation and $\mathrm{Ca}^{2+}$ influx are required for activity-dependent potentiation of $\mathrm{Cx} 35$-mediated electrical coupling at the mixed electrical/chemical synapses in goldfish Mauthner cells (Yang et al., 1990; Pereda and Faber, 1996; Pereda et al., 2003) (Cx35 is the non-mammalian ortholog of mammalian Cx36). Since NMDA receptor blockade strongly reduces AII amacrine cell coupling strength, we investigated whether NMDA receptors were localized near Cx36 gap junctions on AIIs, and thus in a position to influence gap junctional coupling in the AII network. Whole mount retinas were labeled with antibodies against calretinin, the NR1 subunit of NMDA receptors, and Cx36 (Fig. 3A). Nearly all Cx36 gap junctions on AII amacrine cell dendrites were colocalized or closely associated with NR1 puncta (Fig. 3B). Arrows in Figure 3 indicate locations on AII dendrites where $\mathrm{Cx} 36$ gap junctions colocalize with strong NR1 puncta. As before, we analyzed the spatial intensity distribu- tion of fluorescence for each antibody channel, with each square sampling box centered on Cx36 gap junctions on AIIs (Fig. 3D). The central peak seen in all three channel averages indicates the close association of all three signals. NMDA receptors are expressed by a number of retinal neurons with dendrites near to those of AII amacrine cells, such as ON retinal ganglion cells (Zhang and Diamond, 2006), and much of the NR1 labeling seen is not on AII amacrine cells. The association of Cx36 gap junctions with NR1 puncta was not due to chance colocalization with the more numerous NR 1 puncta, however, as $90^{\circ}$ rotation of the NR1 channel relative to the other two channels abolished the associated central peak in the spatial average. As an independent measure we also examined the spatial average centered around the NR1 puncta on AII amacrine cells. The resulting central peak in the Cx36 channel indicates a close association between NMDA receptors and Cx36 gap junctions on AII amacrine cells (Fig. 3E). Thus, NMDA receptors are appropriately localized to influence the coupling state of the AII amacrine network by modulating Cx36 gap junctions.

\section{An NMDA receptor-driven signaling pathway regulates phosphorylation of $\mathrm{Cx} 36$ in AII amacrine cells}

To elucidate the signaling mechanism that regulates coupling, we used an experimental paradigm we developed to assess the coupling state of $\mathrm{Cx} 36$ gap junctions by examining the relative phosphorylation state of Cx36 at Ser293 (Cx36-P) (Kothmann et al., 2009). Using this paradigm, we previously found that increased phosphorylation of Cx36 at Ser293, a site that regulates coupling through these gap junctions (Ouyang et al., 2005), is strongly correlated with increased coupling in the AII amacrine cell network. For the current experiments the superior portion of a lightadapted rabbit eyecup was cut into four retina-sclera pieces. These were incubated for $20 \mathrm{~min}$ in control Ames or Ames with glutamate receptor antagonist(s) added, and changes in phosphorylation were measured using an antibody specific for phospho-Ser293-Cx36 (Kothmann et al., 2007). Cx36-P was quantified as the average ratio of phospho-Ser293-Cx36 antibody fluorescence to monoclonal Cx36 antibody fluorescence at each individual gap junction plaque (for full details on Cx36-P quantification, see Materials and Methods). Phosphorylation of Cx36 plaques on AII amacrine cells was heterogeneous in light-adapted retina (Fig. $4 A$ ). Application of the NMDA receptor antagonist CPP $(10 \mu \mathrm{M})$ reduced mean Cx36-P by $60 \%$ (Fig. $4 B, E$ ), indicating that activation of NMDA receptors in light-adapted retina acts to increase phosphorylation of $\mathrm{Cx} 36$. Coapplication of the AMPA receptor antagonist NBQX $(10 \mu \mathrm{M})$ with CPP caused a similar reduction in Cx36-P (Fig. 4C,E).

Dopamine is a well known regulator of coupling in the AII amacrine cell network (Hampson et al., 1992), with increased dopamine signaling causing reduced $\mathrm{Cx} 36-\mathrm{P}$ and reduced coupling (Kothmann et al., 2009). We tested whether the effect of NMDA receptor blockade on Cx36-P was due to modulation of neurons influencing dopamine release in the retina by repeating the experiment with the dopamine D1 receptor antagonist SCH23390 $(50 \mu \mathrm{M})$ in the bath. D1 receptor blockade alone increased Cx36-P, as we reported previously (Kothmann et al., 2009), but it did not prevent the reduction in Cx36-P caused by CPP (Fig. $4 F$ ). As before, inclusion of NBQX in the bath had no additional effect. Thus, blockade of NMDA receptors is sufficient to reduce phosphorylation of Cx36 in AII amacrine cells in lightadapted retina, and it is independent of the dopaminergic pathway which also regulates Cx36-P in AIIs. 

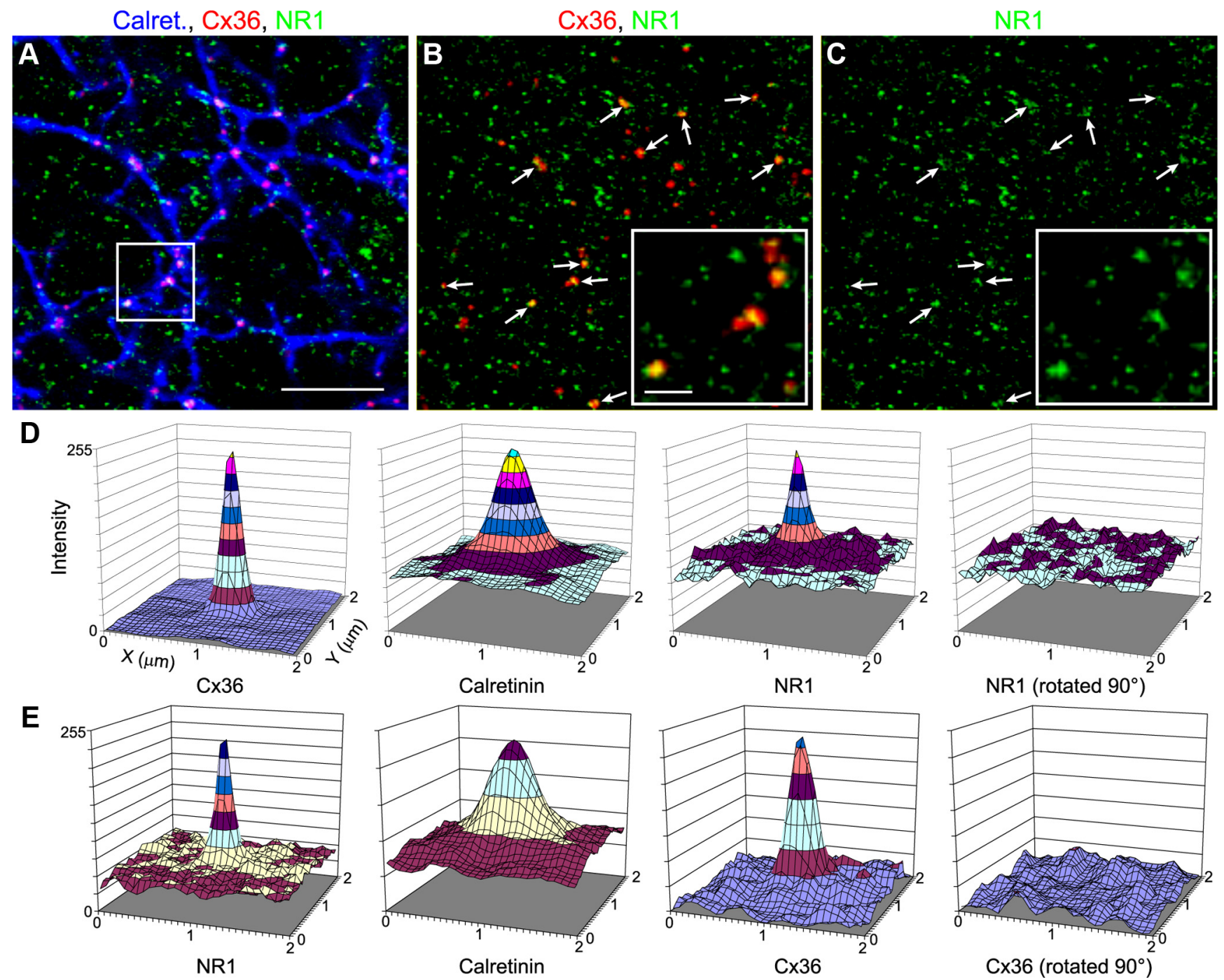

Figure 3. NMDA receptors colocalize with (x36 gap junctions on All amacrine cells. A, Triple labeled imaged shows All amacrine cells labeled by calretinin antibodies (blue), Cx36 gap junctions (red), and NMDA receptors labeled with NR1 antibodies (green). White pixels indicate the colocalization of strong signals in all three channels. The box indicates the area of the insets in subsequent panels. $\boldsymbol{B}$, Arrows indicate the locations of selected X $x 36$ gap junctions. Yellow pixels indicate colocalization of strong $X 36$ and NR1 signals. $C$, The arrows showing the locations of $C \times 36$ gap junctions show that NR1 puncta are colocalized with most $C \times 36$ gap junctions on the All network. $D$, Analysis of the average fluorescent signals spatially associated with 228 Cx36 puncta on All dendrites. The existence of peaks in all three signals indicates that $\mathrm{C} \times 36$ and NMDA receptors are spatially associated on All dendrites. Reanalysis after rotation of the NR1 channel by $90^{\circ}$ abolishes the peak for the NR1 signal, indicating that the association between NR1 and CX36 signals did not occur by chance due to the more numerous NR1 puncta. $E$, Analysis of the average fluorescent signals spatially associated with NR1 puncta on All dendrites. The existence of peaks in all three signals indicates that the majority of NR1 puncta on All dendrites are spatially associated with CX36 gap junctions. Scale bars: $\boldsymbol{A}, 10 \mu \mathrm{m} ; \boldsymbol{B}$ inset, $2 \mu \mathrm{m}$.

In the Mauthner cell of the goldfish, electrical synapses with afferent fibers are potentiated by activation of adjacent NMDA receptors and the resultant $\mathrm{Ca}^{2+}$ influx. This activity-dependent potentiation also requires CaMKII activation (Pereda et al., 1998). We therefore tested whether inhibition of CaMKII influenced the phosphorylation state of Cx36 gap junctions on AII amacrine cells. Application of the CaMKII inhibitor KN-93 (10 $\mu \mathrm{M})$ reduced mean Cx36-P to a similar extent as blockade of NMDA receptors (Fig. 4D,E). As was the case with NMDA receptor blockade, the reduction in Cx36-P caused by KN-93 persisted with dopamine D1 receptor antagonist in the bath (Fig. $4 F$ ), indicating that CaMKII inhibition reduces $\mathrm{Cx} 36-\mathrm{P}$ independent of dopamine signaling. These experiments indicate that in light-adapted retina, activation of NMDA receptors and CaMKII activity are both required to maintain phosphorylation of $\mathrm{Cx} 36$ at Ser293.

\section{Activated CaMKII colocalizes with Cx36 gap junctions in AII amacrine cells}

CaMKII is a common mediator of activity-dependent plasticity in neurons (Colbran and Brown, 2004). To maintain specificity of targeting, CaMKII is localized in the postsynaptic density found at glutamatergic synapses, where it often serves as an effector of $\mathrm{Ca}^{2+}$ influx through NMDA receptors (Wayman et al., 2008). CaMKII binds to multiple subunits of the NMDA receptor as well as to Cx36 gap junctions, and this binding is either facilitated by or requires autophosphorylation of the kinase at Thr286 (Colbran, 2004; Alev et al., 2008). Additionally, CaMKII shows variable labeling and colocalization with $\mathrm{C} \times 35$ at the mixed electrical/chemical synapses onto Mauthner cells, suggesting that CaMKII may account for the variable conductances of individual electrical synapses onto a single Mauthner cell (Flores et al., 2010). We used antibodies against phospho-Thr286-CaMKII, 

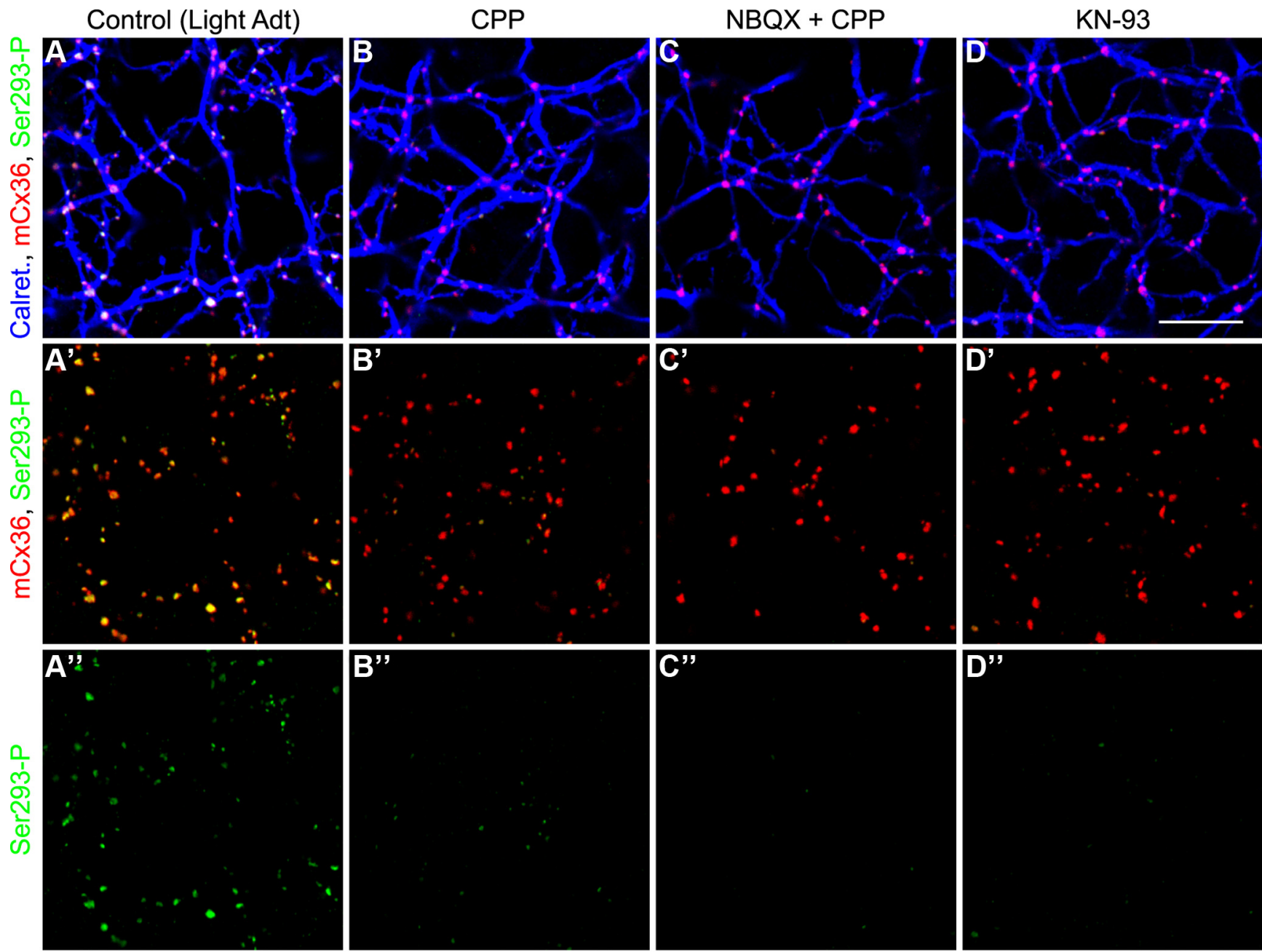

E

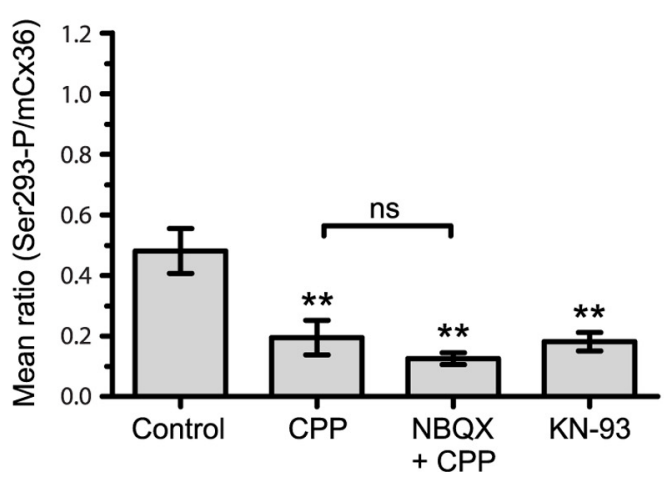

F

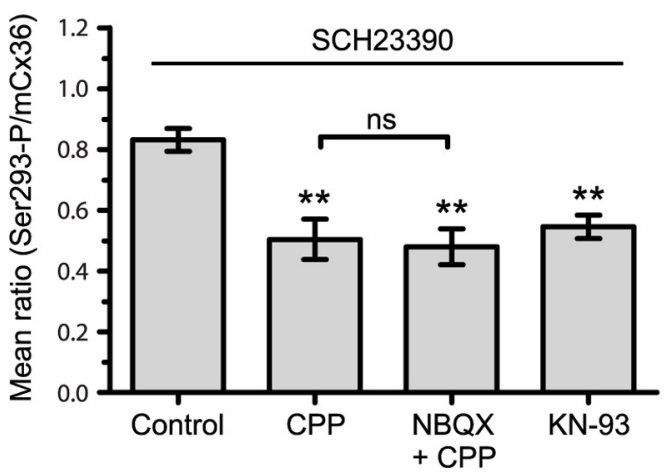

Figure 4. Blockade of NMDA receptors and inhibition of CaMKII reduce phosphorylation of Cx36 gap junctions on All amacrine cells. $\boldsymbol{A}-\boldsymbol{A}^{\prime \prime}$, Phosphorylation of $C \times 36$ at Ser293 was heterogeneous in light-adapted retina. $\boldsymbol{B}-\boldsymbol{B}^{\prime \prime}$, Blockade of NMDA receptors (CPP, $10 \mu \mathrm{m}$ ) reduced phosphorylation of CX36 at Ser293. $\boldsymbol{C}-\boldsymbol{C}^{\prime \prime}$, Blockade of AMPA/kainate (NBQX, 10 $\mu \mathrm{M}$ ) and NMDA receptors had little additional effect over blockade of NMDA receptors alone. $\boldsymbol{D}-\boldsymbol{D}^{\prime \prime}$, Inhibition of CaMKII (KN-93, $10 \mu \mathrm{M}$ ) reduced phosphorylation of $(x 36$ at Ser293. $\boldsymbol{E}$, Summary of experiments $(n=4)$ shows that blockade of NMDA receptors significantly reduced mean phosphorylation of Cx36 on All amacrine cells. Blockade of AMPA receptors in addition to NMDA receptors did not significantly increase the reduction. Inhibition of CaMKII reduced phosphorylation of C 36 to a similar extent as NMDA receptor blockade. $\boldsymbol{F}$, The experiments summarized in $\boldsymbol{E}$ were repeated with antagonist of dopamine D1 receptors (SCH23390, $50 \mu \mathrm{m})$ in the bath $(n=6)$. As shown previously, antagonism of D1 receptors increased mean phosphorylation of Cx36 on Alls. It did not prevent the effects of NMDA receptor blockade or CaMKII inhibition, indicating that both of the effects are independent of dopaminergic input to All amacrine cells. Analysis was performed on single optical sections; images presented are 1- $\mu \mathrm{m}$-deep $z$-stacks. Error bars indicate SEM; asterisks denote statistical difference from control values unless otherwise indicated, ${ }^{* *} p<0.01$. Scale bar $(\boldsymbol{D}), 10 \mu \mathrm{m}$.

calretinin, and $\mathrm{Cx} 36$ to determine whether the activated kinase is localized near Cx36 gap junctions in AII amacrine cells. In vertical sections from light-adapted retina there was variable phospho-Thr286-CaMKII labeling throughout the IPL (Fig. 5). The somas of a number of cells were ringed with phosphoThr286-CaMKII labeling, including many AII amacrine cells. Activated CaMKII labeling was strong in the primary dendrites of
AIIs as well. Close inspection of the fine dendrites of AIIs in sublamina $\mathrm{b}$ of the IPL (Fig. 5A, box) showed that Cx36 gap junctions on the AII network were often colocalized with hotspots of phospho-Thr286-CaMKII labeling (Fig. 5D). Furthermore, the phosphorylation state of CaMKII in the immediate vicinity of Cx36 gap junctions was variable, consistent with the variable levels of Cx36 phosphorylation seen at these gap junc- 

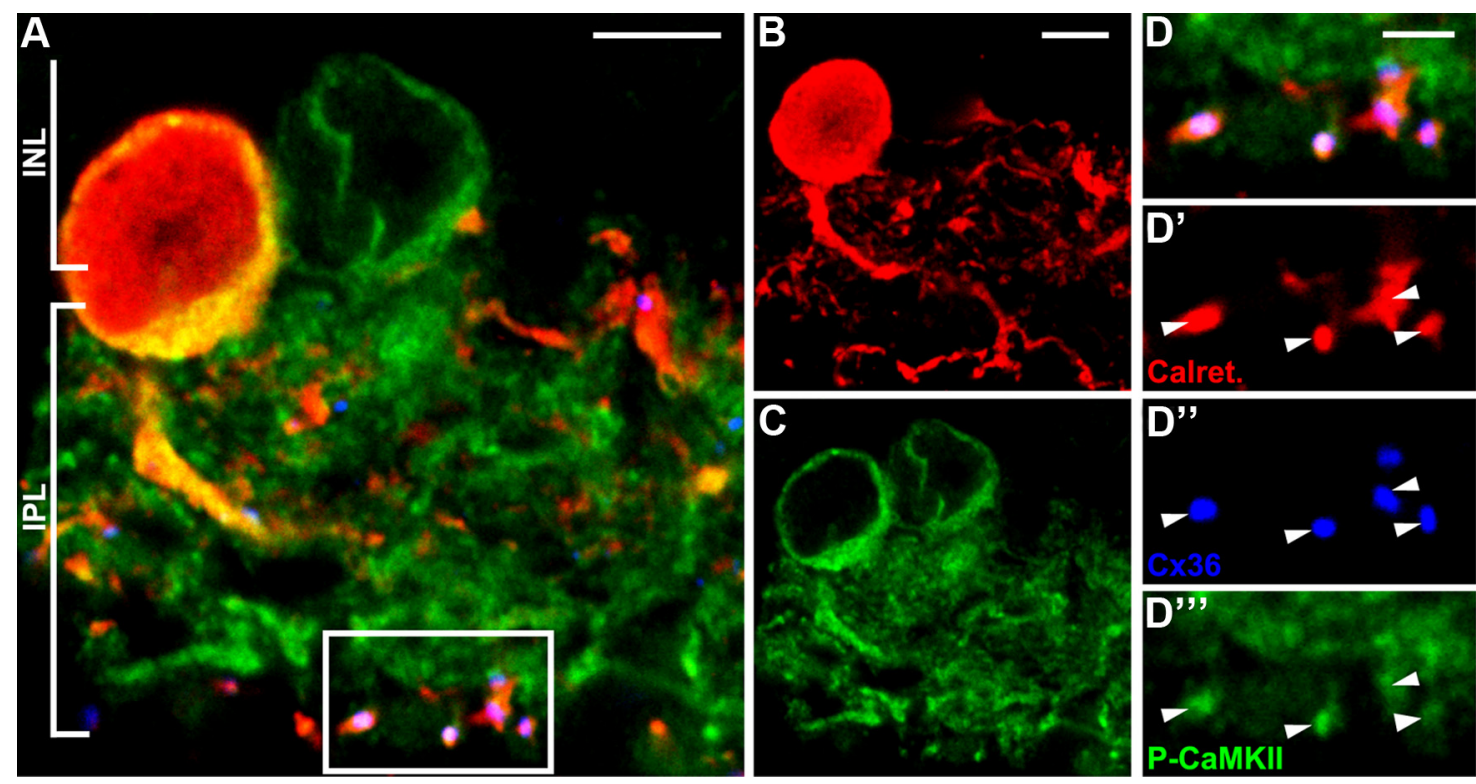

Figure 5. Activated CaMKII "hotspots" colocalize with Cx36 gap junctions on All amacrine cell dendrites. A, A single optical confocal section showing that activated CaMKII, identified by antibodies against phospho-Thr286-CaMKII (green), is widely distributed throughout the IPL of light-adapted retina. Strong labeling is seen in a ring around the soma of a calretinin-labeled All amacrine cell (red) in the inner nuclear layer (INL), as well as in its stout primary dendrite (yellow). $\boldsymbol{B}, \mathrm{A} 6-\mu \mathrm{m}$-deep z-stack of the calretinin label showing more fully the primary dendrite of the All descending through the IPL and branching into fine dendrites. $C$, A single optical confocal section showing only the activated CaMKII label. $\boldsymbol{D}-\boldsymbol{D}^{\prime \prime \prime}$, High-magnification views of the area enclosed in the white rectangle in $\boldsymbol{A}$. These single optical confocal sections show cross-sections through several of the fine dendrites of the All amacrine cell $\left(\boldsymbol{D}^{\prime}\right)$, and the $\left(\times 36\right.$ gap junctions (blue) on them ( $\left.\boldsymbol{D}^{\prime \prime}\right)$. Several of the $\mathrm{C} \times 36$ gap junctions are indicated by arrowheads, and when the activated CaMKII label is viewed in isolation ( $\left.\boldsymbol{D}^{\prime \prime \prime}\right)$, it is evident that several of these $(\times 36$ gap junctions are colocalized with "hotspots" of activated CaMKII. Scale bars: $\boldsymbol{A}, \boldsymbol{B}, 5 \mu \mathrm{m} ; \boldsymbol{D}, 2 \mu \mathrm{m}$.

tions. These results indicate that activated CaMKII is appropriately localized to influence the phosphorylation state of Cx36 gap junctions on AII amacrine cells, either by direct phosphorylation of Cx36 or by modulation of other proteins regulating Cx36 phosphorylation.

\section{NMDA receptors drive phosphorylation of Cx36 on AII amacrine cells}

We next asked whether activation of NMDA receptors could drive increased phosphorylation of $\mathrm{Cx} 36$ gap junctions. For these experiments we began by dark-adapting the superior portion of a rabbit eyecup for $100 \mathrm{~min}$. The purpose for this was twofold. First, AII amacrine cells in well dark-adapted retinas have been shown to be relatively uncoupled (Bloomfield et al., 1997; Bloomfield and Völgyi, 2004). Thus we wished to investigate the phosphorylation state of Cx36 in AIIs when retina-sclera preparations were dark-adapted. Second, as rod bipolar cells are ONtype bipolar cells that release glutamate in response to light, using dark-adapted retinas allowed us to examine the effects of NMDA application on relatively quiescent AII amacrine cells. After the initial dark-adaptation period, the eyecup was removed from the light-tight chamber under infrared illumination and cut into four retina-sclera pieces. Pieces were separated into control Ames or Ames with glutamate agonist(s) added and placed back into the light-tight chamber for 20 additional minutes, after which phosphorylation of $\mathrm{Cx} 36$ was measured as before. Dark-adapting the retina for $120 \mathrm{~min}$ led to extremely low baseline Cx36-P (Fig. $6 A, E$ ), in good agreement with the previous reports that AIIs are uncoupled in well dark-adapted retinas (Bloomfield et al., 1997; Bloomfield and Völgyi, 2004). Mean Cx36-P in dark-adapted retina was reduced by $90 \%$ compared with typical values obtained in light-adapted retinas (compare Fig. 6A, $E$ with Fig. $4 A, E)$. Addition of NMDA $(50 \mu \mathrm{M})$ to the bath increased Cx36-P back to typical light-adapted levels (Fig. $6 B, E$ ), indicating that
NMDA receptor activation drives phosphorylation of Cx36. Addition of both AMPA $(5 \mu \mathrm{M})$ and NMDA $(50 \mu \mathrm{M})$ to the bath increased Cx36-P significantly above the levels caused by application of NMDA alone (Fig. 6C,E). Interestingly, application of AMPA $(5 \mu \mathrm{M})$ alone also increased Cx36-P (Fig. 6D,E).

One possible explanation for the increase in $\mathrm{Cx} 36-\mathrm{P}$ in response to AMPA application is that AMPA receptor-driven depolarization of AII amacrine cells facilitated opening of NMDA receptors near Cx36 gap junctions. We tested this by applying AMPA while either blocking NDMA receptors pharmacologically or manipulating the extracellular $\mathrm{Mg}^{2+}$ concentration (Fig. $6 F)$. The AMPA $(5 \mu \mathrm{M})$-driven increase in $\mathrm{Cx} 36-\mathrm{P}$ was blocked both by the NMDA antagonist CPP $(10 \mu \mathrm{M})$ and by raising the extracellular $\mathrm{Mg}^{2+}$ concentration to $4 \mathrm{~mm}$. These conditions strongly suggest that NMDA receptor activation is required for the AMPA-driven increase in Cx36-P. Considered together, these two sets of experiments suggest that presynaptic activity plays an important role in modulation of AII amacrine cell coupling via NMDA receptor-driven increases in phosphorylation of Cx36.

\section{Blockade of glutamate transporters increases Cx36 phosphorylation}

In considering the possibility that the AMPA-driven increase in Cx36-P was due to depolarization of AII amacrine cells and required NMDA receptor activation, we made the assumption that there was sufficient glutamate present at the NMDA receptors to activate them. Since NMDA receptors on AIIs are nonsynaptic (Fig. 2), there are two potentially overlapping sources for such extracellular glutamate: spillover from nearby ON-type bipolar cell axon terminals, and ambient extracellular glutamate. Thus, when we designed the experiments to test the dependence of AMPA-driven increases in Cx36-P on NMDA receptor activation, we included an additional condition, "zero" extracellular $\mathrm{Mg}^{2+}$ (hereon $0 \mathrm{Mg}^{2+}$ ), to test whether there was sufficient am- 


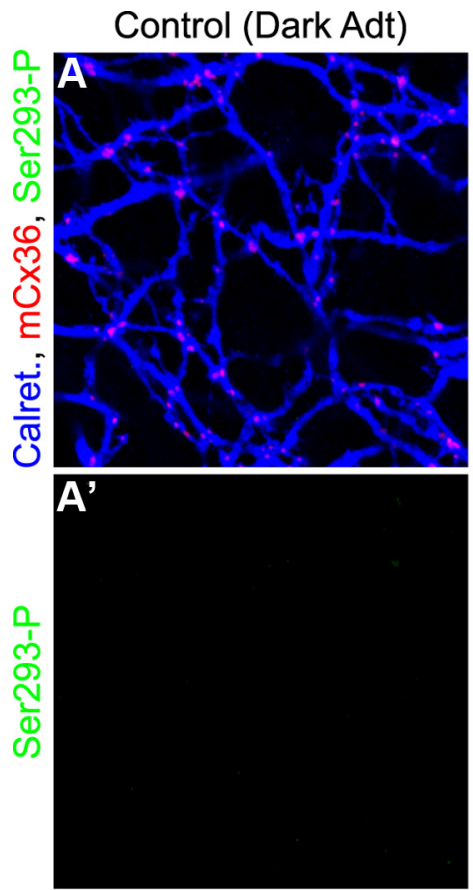

E

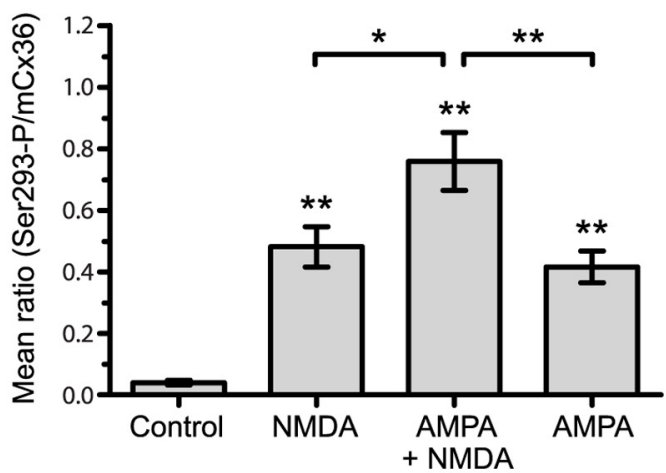

NMDA
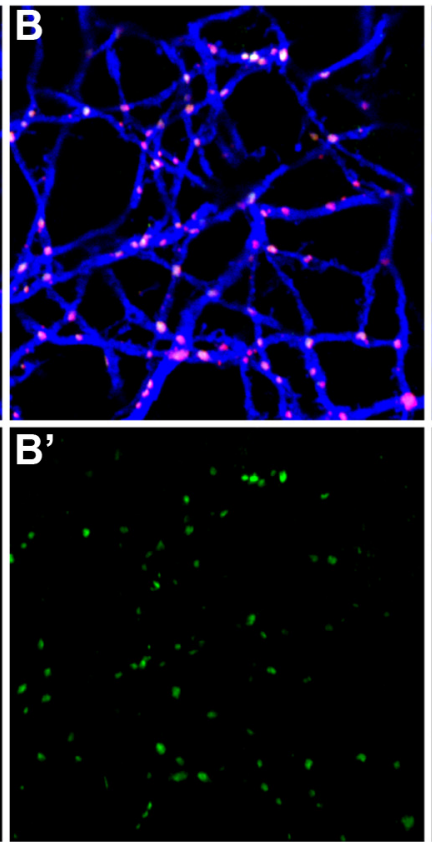

F
AMPA + NMDA
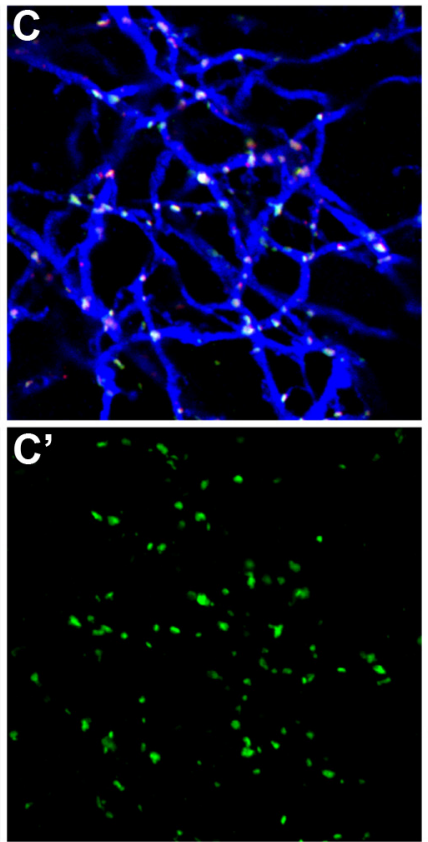

\section{AMPA}
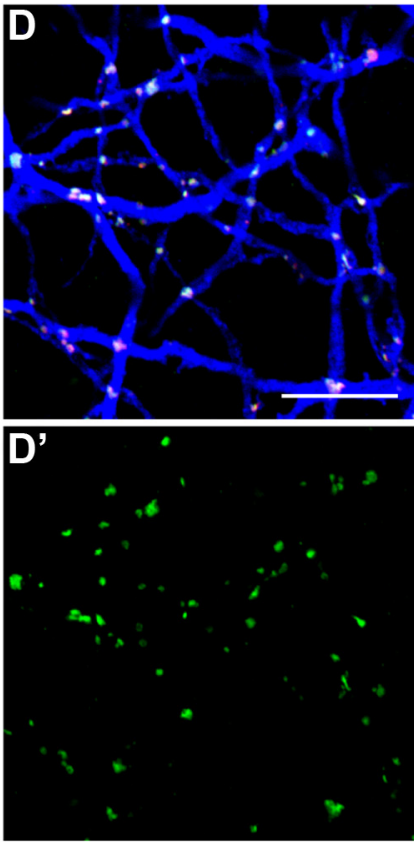

ns

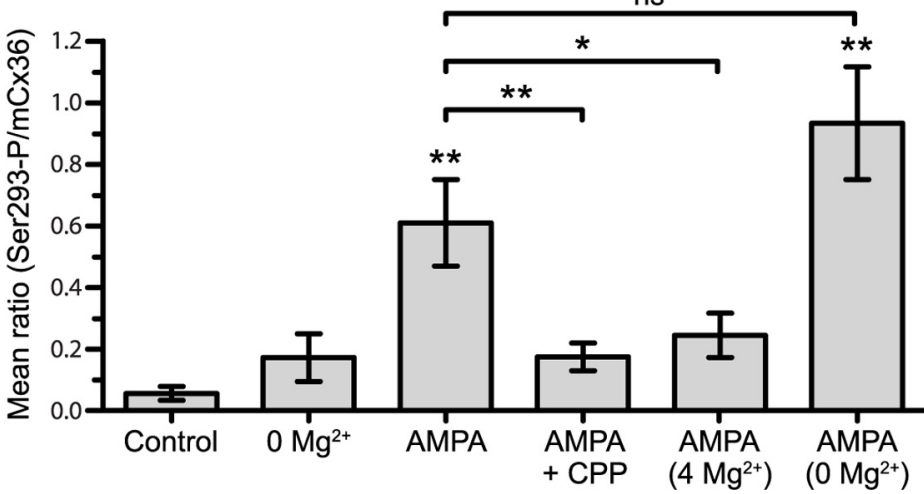

Figure 6. Activation of NMDA receptors drives phosphorylation of $\mathrm{Cx} 36$ gap junctions on All amacrine cells. $\boldsymbol{A}, \boldsymbol{A}^{\prime}$, Dark adaptation of the retina for $2 \mathrm{~h}$ greatly reduced phosphorylation of $C \times 36$ gap junctions at Ser293. $\boldsymbol{B}, \boldsymbol{B}^{\prime}$, Application of NMDA (50 $\left.\mu \mathrm{m}\right)$ drove increased phosphorylation of $\left(x 36\right.$ at Ser293. $\boldsymbol{C}, \boldsymbol{C}^{\prime}$, Addition of AMPA (5 $\left.\mu \mathrm{m}\right)$ and NMDA drove increased phosphorylation of $(x 36$ at Ser293 more strongly than NMDA did alone. $\boldsymbol{D}, \boldsymbol{D}^{\prime}$, Interestingly, application of AMPA alone also drove increased phosphorylation of $(x 36$ at Ser293. $\boldsymbol{E}$, Summary of experiments $(n=6)$ shows that addition of NMDA to the bath drove phosphorylation of (x36 back to control, light-adapted levels (compare with Fig. 4E). Application of AMPA drove increased phosphorylation as much as NMDA did. Addition of AMPA and NMDA drove phosphorylation significantly higher than NMDA or AMPA alone. $\boldsymbol{F}$, The AMPA-driven increase in Ser293 phosphorylation was prevented by blockade of NMDA receptors (AMPA, $5 \mu \mathrm{m}$, plus (PP, $10 \mu \mathrm{m}$ ) or by increasing the concentration of extracellular $\mathrm{Mg}^{2+}$ to 4 mM, indicating that NMDA receptor activation mediates the AMPA-driven increase in phosphorylation. Nominal removal of $\mathrm{Mg}^{2+}$ did not significantly increase phosphorylation over baseline levels (but see Results). Analysis was performed on single optical sections; images presented are 1- $\mu \mathrm{m}$-deep $z$-stacks. Error bars are SEM; asterisks denote statistical difference from control values unless otherwise indicated, ${ }^{*} p<0.05,{ }^{* *} p<0.01$. Scale bar $(\boldsymbol{D}), 10 \mu \mathrm{m}$.

bient glutamate to activate NMDA receptors on AIIs (since the retina was dark-adapted and held in a light-tight box, we reasoned that spillover from ON-type bipolar cells would be less likely to contribute to extracellular glutamate). Since retinasclera pieces were transferred from dark adaptation in normal $\mathrm{Mg}^{2+}$ Ames medium (1.2 $\mathrm{mm} \mathrm{Mg}^{2+}$ ) into $0 \mathrm{Mg}^{2+}$ Ames medium for the treatment, this condition was only nominally 0 $\mathrm{Mg}^{2+}$, as a small volume of the normal Ames was introduced into the treatment bath along with the retina-sclera piece. We estimate that the dilution of normal $\mathrm{Mg}^{2+}$ Ames accompanying the transfer of tissue was at minimum 50-fold, and likely closer to 100fold, yielding an estimated final $\mathrm{Mg}^{2+}$ concentration between 12 and $24 \mu \mathrm{M}$.

However, we found that simply transferring the retina into 0 $\mathrm{Mg}^{2+}$ Ames did not significantly alter Cx36-P in dark-adapted retina (Fig. $6 F$ ). This would seem to indicate that the additional depolarization provided by a subsaturating concentration of
AMPA was necessary to trigger elevated Cx36-P. We also tested whether application of AMPA $(5 \mu \mathrm{M})$ in $0 \mathrm{Mg}^{2+}$ Ames would have a potentiating effect on $\mathrm{Cx} 36-\mathrm{P}$, similar to the coapplication of AMPA and NMDA. While this led to an increase in mean level of $\mathrm{Cx} 36-\mathrm{P}$ that was qualitatively similar to the increase observed with coapplication of AMPA and NMDA (compare Fig. 6E,F), it was not statistically distinguishable from AMPA ( $5 \mu \mathrm{M})$ in normal $\mathrm{Mg}^{2+}$ Ames. Thus, it appears that in dark-adapted retina ambient glutamate alone is not sufficient to modulate $\mathrm{Cx} 36-\mathrm{P}$, but rather that some amount of depolarization may be required along with activation of NMDA receptors.

We used one additional approach to examine the sensitivity of Cx36-P to extracellular glutamate. We applied threo- $\beta$ benzyloxyaspartic acid (TBOA; $50 \mu \mathrm{M})$ in light-adapted retina to block glutamate transporters and thus elevate the concentration of extracellular glutamate. Since many more ON-type bipolar cells should be active in light-adapted retina under 

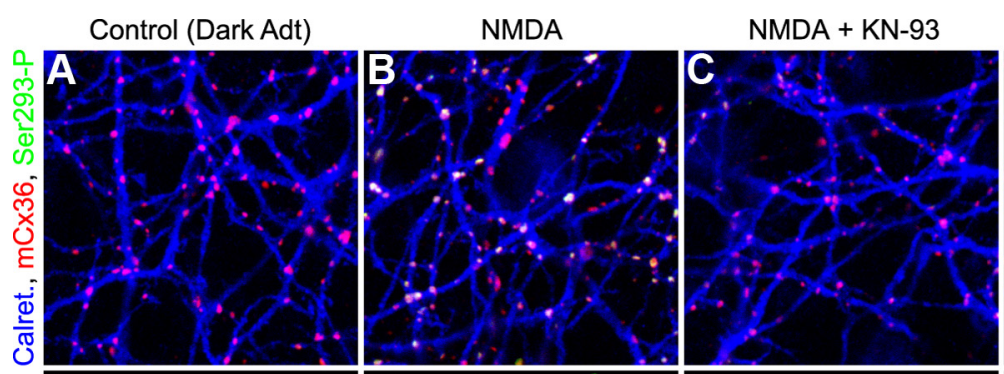

NMDA + Thapsigargin
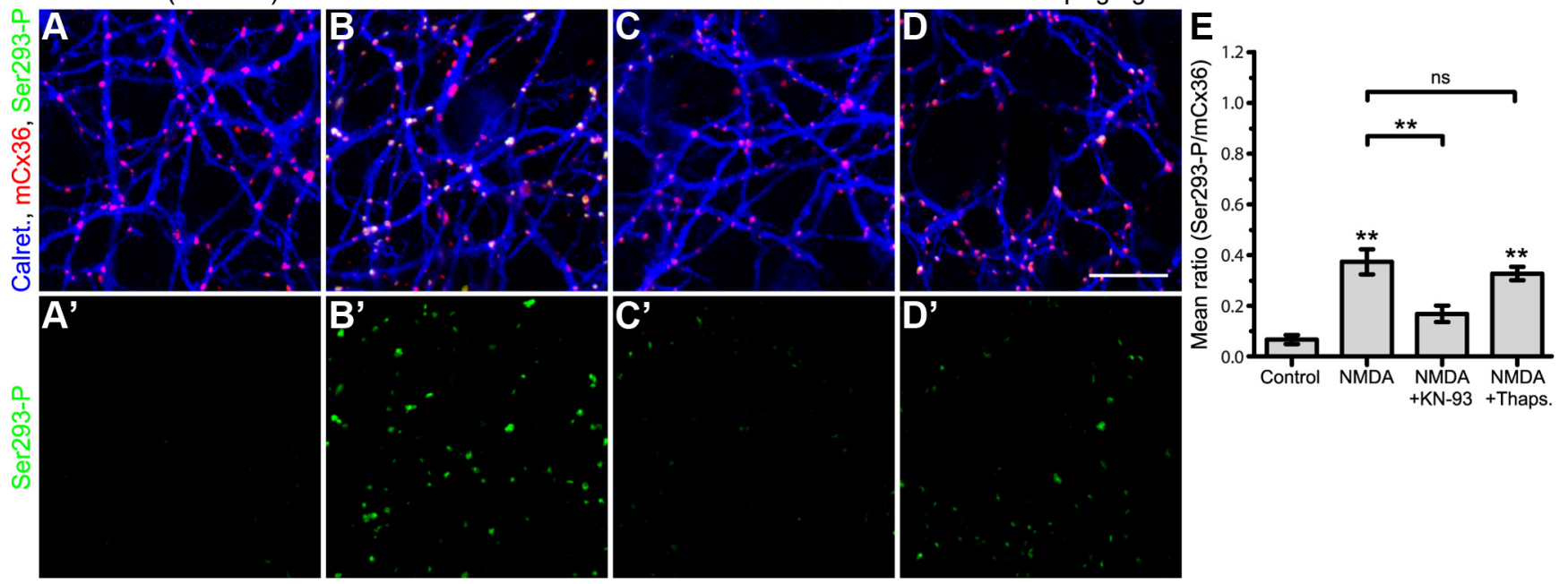

Figure 7. CaMKII is required for NMDA-driven phosphorylation of C 36 gap junctions on All amacrine cells. $A, A^{\prime}$, Dark adaptation of the retina for $2 \mathrm{~h}$ greatly reduced phosphorylation of $C \times 36$ gap junctions at Ser293. $\boldsymbol{B}$, and $\boldsymbol{B}^{\prime}$, Application of NMDA $(50 \mu \mathrm{M})$ drove increased phosphorylation of $\mathbf{C} 36$ at Ser293. $\boldsymbol{C}, \boldsymbol{C}^{\prime}$, The NMDA-driven increase in Ser293 phosphorylation was prevented by inhibition of CaMKII with KN-93 $(10 \mu \mathrm{M})$. D, $\boldsymbol{D}^{\prime}$, Depletion of intracellular $\mathrm{Ca}^{2+}$ stores with thapsigargin $(1 \mu \mathrm{m})$ did not significantly alter the NMDA-driven increase in phosphorylation of $\mathrm{C} \times 36$ at Ser293. E, Summary of experiments $(n=5)$ shows that inhibition of CaMKII blocked the NMDA-driven increase in phosphorylation of $\mathrm{C}_{3} 36$ at Ser293. Inhibition of $\mathrm{Ca}^{2+}{ }_{\text {-induced } \mathrm{Ca}^{2+}}{ }_{\text {release did }}$ not significantly alter NMDA-driven increases in Ser293 phosphorylation. Together, these results argue that $\mathrm{Ca}^{2+}$ influx through NMDA receptors is sufficient to activate CaMKII, which leads to increased phosphorylation of local $\mathrm{C}$ 36. Analysis was performed on single optical sections; images presented are 1- $\mu \mathrm{m}$-deep $z$-stacks. Error bars are SEM, asterisks denote statistical difference from control values unless otherwise indicated, ${ }^{* *} p<0.01$. Scale bar (D), $10 \mu \mathrm{m}$.

normal room lights than in dark-adapted retina held in a lighttight box, this approach was better suited to determine whether $\mathrm{Cx} 36-\mathrm{P}$ is modulated by extracellular glutamate at all. There was an intermediate level of $\mathrm{Cx} 36-\mathrm{P}$ in control lightadapted retina (mean ratio phospho- $\mathrm{Ab} / \mathrm{mCx} 36 \mathrm{Ab}$ of $0.34 \pm$ $0.17 \mathrm{SD}$ ), as seen in all other light-adapted experiments. TBOA significantly increased Cx36-P (mean ratio of $0.57 \pm 0.12 \mathrm{SD}$ ); the effect of TBOA was blocked by CPP $(10 \mu \mathrm{M})$ (mean ratio of $0.13 \pm 0.052 \mathrm{SD}$ ), which as before reduced $\mathrm{Cx} 36-\mathrm{P}$ compared with control levels (one-way repeated-measures ANOVA, $F_{(2,4)}=21.33, p=0.0006$; Bonferroni's multiple-comparison tests: control vs TBOA, $p<0.05$; control vs TBOA $+\mathrm{CPP}, p<$ 0.05 ; ТBOA vs TBOA + CPP, $p<0.01)$. These experiments show that $\mathrm{Cx} 36-\mathrm{P}$ is sensitive to the concentration of extracellular glutamate, and that NMDA receptors must be available for this sensitivity to be maintained.

\section{CaMKII is required for NMDA-driven increases in Cx36 phosphorylation}

To follow up on the previous sets of experiments, we tested whether CaMKII activation was necessary for NMDA-driven increases in phosphorylation of Cx36. Additionally, since $\mathrm{Ca}^{2+}$ influx through NMDA receptors has been linked to $\mathrm{Ca}^{2+}$-induced $\mathrm{Ca}^{2+}$ release (CICR) in some glycinergic amacrine cells (Chávez and Diamond, 2008), we also tested whether depletion of endoplasmic reticulum $\mathrm{Ca}^{2+}$ stores could reduce the amplitude of NMDA-driven increases in Cx36 phosphorylation. We again used the superior portion of dark-adapted eyecups for these experiments, and as before dark-adapting the retina led to extremely low baseline levels of Cx36-P (Fig. $7 A, E)$ while addition of NMDA $(50 \mu \mathrm{M})$ to the bath for the final 20 min of the dark-adaptation period increased Cx36-P back to typical light-adapted levels (Fig. $7 \mathrm{~B}, E)$. Coapplication of the CaMKII inhibitor KN-93 (10 $\mu \mathrm{M})$ with NMDA prevented the NMDA-driven increase in Cx36-P (Fig. $7 C, E$ ). Thus, CaMKII is required for normal NMDAdriven phosphorylation of $\mathrm{Cx} 36$. We also applied thapsigargin
$(1 \mu \mathrm{M})$ to a retina-sclera piece for $30 \mathrm{~min}$ before addition of NMDA to the bath to deplete endoplasmic reticulum $\mathrm{Ca}^{2+}$ stores. This treatment had no effect on the NMDA-driven increase in Cx36 phosphorylation (Fig. $7 D, E$ ), indicating that $\mathrm{Ca}^{2+}$ influx through NMDA receptors was sufficient to drive increased Cx36 phosphorylation without stimulating CICR.

\section{ON-Bipolar cell activation and background light increment} drive phosphorylation of Cx36 on AII amacrine cells

Finally, we tested whether activation of ON-type bipolar cells could drive increased phosphorylation of $\mathrm{Cx} 36$ gap junctions on AII amacrine cells. Rod bipolar cells provide the major glutamatergic ON input to AIIs on their fine dendrites (Strettoi et al., 1992), near where the Cx36 gap junctions and NMDA receptors are located, but as we noted previously, on average synaptic ribbons in ON-type cone bipolar cells are as close or closer to NR1 puncta on AIIs (disregarding any obstructive neuropil which might lie in between). In these experiments we depolarized all ON-type bipolar cells (both rod- and conedriven), either pharmacologically with the mGlur6 antagonist $(R S)$ - $\alpha$-cyclopropyl-4-phosphonophenylglycine (CPPG) or directly with a light increment. The experimental setup was the same as described for the above experiments using darkadapted retina, and dark-adapting the retina led to low baseline levels of Cx36-P (Fig. 8A,E). Addition of CPPG (200 $\mu \mathrm{M})$ to the bath for the final $20 \mathrm{~min}$ of the dark-adaptation period increased mean Cx36-P (Fig. 8 B,E) to levels similar to those in light-adapted retina. Exposure of the dark-adapted retina to photopic white light (flux of $22.9 \times 10^{4}$ photons $\mu \mathrm{m}^{-2} \mathrm{~s}^{-1}$; the same source as used for all light-adapted experiments) for the final $15 \mathrm{~min}$ of the dark-adaptation period increased Cx36-P (Fig. 8C,E) back to typical light-adapted levels. Addition of the mGluR6 agonist L-AP4 $(50 \mu \mathrm{M})$, which hyperpolarizes ON-type bipolar cells, to the bath $5 \mathrm{~min}$ before light exposure blocked the increase in Cx36-P (Fig. $8 D, E$ ). These experiments show that increments in background lighting, mediated by ON-type bipolar cells, drive increased phosphor- 

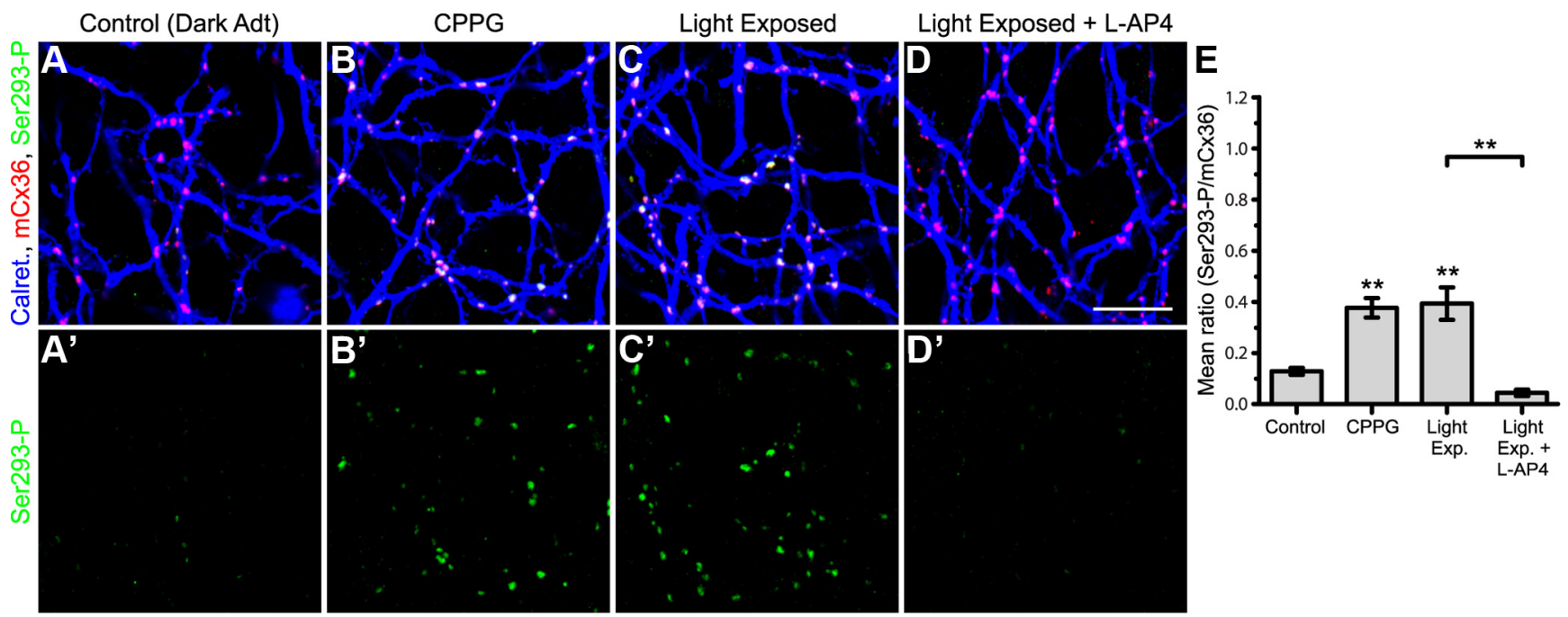

Figure 8. Activation of ON-bipolar cells by CPPG or background light increment drive increased phosphorylation of ( $x 36$ gap junctions on All amacrine cells. $A, A^{\prime}$, Dark adaptation of the retina for $2 \mathrm{~h}$ greatly reduced phosphorylation of (x36 gap junctions at Ser293. B, $\boldsymbol{B}^{\prime}$, Depolarization of ON-type bipolar cells in darkness via antagonism of mGluR6 receptors (CPPG, $200 \mu \mathrm{M}$ ) drove increased phosphorylation of $\mathrm{C} \times 36$ at Ser293. C, $\boldsymbol{C}^{\prime}$, Exposure of dark-adapted retinas to photopic full-field background illumination also drove increased phosphorylation of $\mathbf{C x 3 6}$ at Ser293. D, $\mathbf{D}^{\prime}$, The effect of increased background illumination was abolished when activation of ON-type bipolar cells was inhibited (L-AP4, $50 \mu \mathrm{M})$. $\boldsymbol{E}$, Summary of experiments ( $n=5$ ) shows that activation of ON-type bipolar cells drove phosphorylation of $\mathrm{X} 36$ back to control, light-adapted levels (compare with Fig. 4E). Exposure of dark-adapted retinas to photopic background illumination drove phosphorylation to a similar extent as $0 \mathrm{~N}$-type bipolar cell activation did. Activation of mGluR6 receptors on 0N-type bipolar cells completely prevented the effects of increased background illumination, and actually reduced phosphorylation below control, dark-adapted levels (Fig. 5E, but compare with dark-adapted levels). Analysis was performed on single optical sections; images presented are 1- $\mu \mathrm{m}$-deep $z$-stacks. Error bars indicate SEM, asterisks denote statistical difference from control values unless otherwise indicated, ${ }^{* *} p<0.01$. Scale bar $(\boldsymbol{D}), 10 \mu \mathrm{m}$.

ylation of Cx36 on AII amacrine cells, just as increases in background illumination strengthen coupling between AII amacrine cells (Bloomfield et al., 1997; Bloomfield and Völgyi, 2004), and confirm the link between presynaptic activity and Cx36 phosphorylation.

\section{Discussion}

Although NMDA currents were described in AII amacrine cells previously (Hartveit and Veruki, 1997; Zhou and Dacheux, 2004), the physiological significance of these currents was uncertain. We now describe a role for these NMDA receptors in driving increased phosphorylation of Cx36 gap junctions on AIIs, thereby increasing cell-cell coupling in the AII amacrine cell network. Indeed, driving increased phosphorylation of Cx36 may be the primary purpose of NMDA receptors on AIIs.

NMDA receptors on AII amacrine cells contribute minimally or not at all to the postsynaptic response elicited by evoked glutamate release from a presynaptic rod bipolar cell (Singer and Diamond, 2003; Veruki et al., 2003; Trexler et al., 2005). Our anatomical examination confirmed that NMDA receptors on AII amacrine cells are nonsynaptic, in that they are not associated with presynaptic terminals or sites of glutamate release, but instead colocalize with Cx36 gap junctions. Furthermore, NMDA receptors on AIIs are functionally coupled to a pathway driving increased phosphorylation of Cx36 at the regulatory Ser293 site (Ouyang et al., 2005), which promotes increased gap junctional coupling in the AII amacrine cell network (Kothmann et al., 2009), and this pathway requires activation of CaMKII. Cx36 phosphorylation is sensitive to the concentration of extracellular glutamate, and activation of all glutamatergic ON-type bipolar cells drove increased phosphorylation of Cx36 on AIIs. Together, these data describe a mechanism to potentiate Cx36-mediated electrical coupling between neurons via activation of NMDA receptors.

The precise source of glutamate leading to activation of NMDA receptors on AIIs is still unclear, as we found no relation- ship between the NR1 puncta on AIIs and the presynaptic ribbons in rod bipolar cells or nearby ON-type cone bipolar cells. Spillover of glutamate does occur at the rod bipolar-AII synapse (Veruki et al., 2006), but the relatively large mean distance between NR1 puncta and presynaptic ribbons and the high variability in the measure $(3.3 \pm 2.2 \mu \mathrm{m})$ suggests that overall extracellular glutamate "tone" may be an important influence on AII NMDA receptors as well (but see below). Noise analysis has been used to demonstrate the contribution of ambient extracellular glutamate to the excitability of pyramidal neurons in hippocampal slices (Sah et al., 1989) as well as to the basal noise in retinal ganglion cells (Gottesman and Miller, 2003), in both cases via binding to NMDA receptors. Thus, it is conceivable that NMDA receptors on AIIs might detect changes in ambient glutamate. This could explain why addition of AMPA alone was able to drive Cx36 phosphorylation, especially as we found that this still required NMDA receptor activation. However, we found that reducing the $\mathrm{Mg}^{2+}$ block of NMDA receptors in darkadapted retina by itself was not sufficient to drive phosphorylation of Cx36. It may be that the depolarization provided by AMPA application is also important. AIIs express L-type calcium channels, which are primarily localized to their lobular dendrites. However, calcium imaging of AIIs during a depolarizing pulse revealed small $\mathrm{Ca}^{2+}$ elevations in the arboreal dendrites of most cells as well (Habermann et al., 2003). While our experiments show that NMDA receptors are required for AMPA-induced increases in phosphorylation of Cx36 in dark-adapted retina, we cannot exclude the possibility that $\mathrm{Ca}^{2+}$ influx through voltagegated calcium channels is also required under these conditions.

Given that previous studies have not found an NMDA component in the AII EPSC in response to activation of a single presynaptic rod bipolar cell, it may be that multiple nearby bipolar cells must be activated within a short temporal window to sufficiently alter extracellular glutamate concentration for significant NMDA receptor activation. However, since depolarizing a single 
rod bipolar cell causes sufficient spillover to activate glutamate transporters on neighboring rod bipolar cell terminals (Veruki et al., 2006), and that the glutamate transporter in rod bipolar cells (EAAT5; Pow and Barnett, 2000) has a lower affinity for glutamate than does NMDA (64 $\mu \mathrm{M}$ vs $1 \mu \mathrm{M}$; Olverman et al., 1984; Arriza et al., 1997), it seems most likely that NMDA receptors on AIIs do "see" glutamate released by individual rod bipolar cells, even if it does not activate a significant NMDA current. Because spillover from rod bipolar cells seems to have a relatively large diffusion domain, when they release glutamate (particularly when two or more nearby rod bipolar cells release nearly synchronously) it is likely to cause a temporary elevation in ambient glutamate within that domain (since glutamate transport does not fully clear the extracellular glutamate). This is one potential explanation for why we see heterogeneous phosphorylation of Cx36 within individual AII amacrine cells in our light-adapted control conditions (Kothmann et al., 2009). The expression and activity of glutamate transporters in the inner retina, as well as their potential modulation by luminance and adaptation conditions, is no doubt also a crucial component to such a mechanism of NMDA receptor activation. While NMDA currents activated by ambient glutamate would likely be relatively small, they could contribute sufficient $\mathrm{Ca}^{2+}$ influx to activate CaMKII due to the long time constant of deactivation conferred by many NMDA receptor subunits (Cull-Candy et al., 2001).

Application of NMDA to well dark-adapted retina was sufficient to robustly increase $\mathrm{Cx} 36$ phosphorylation, even though AII amacrine cells should be hyperpolarized under this condition and the $\mathrm{Mg}^{2+}$ concentration in our Ames solution was physiological $\left(1.2 \mathrm{mM} \mathrm{Mg}^{2+}\right)$. This may simply be a result of regenerative activation of NMDA receptors in response to a minutes-long exposure to agonist. It is also important to note that compared with many other neurons AIIs have a relatively depolarized resting potential ( $-46 \pm 1.2 \mathrm{mV}$ in dark-adapted retina; Dunn et al., 2006), a potential at which the conductance of NMDA receptors is $\sim 15 \%$ of maximum in $1 \mathrm{~mm} \mathrm{Mg}^{2+}$ (Jahr and Stevens, 1990 , their Fig. 2), and thus some fraction of the receptors should be available to begin with. NR2 subunits also significantly alter the $\mathrm{Mg}^{2+}$ sensitivity of NMDA receptors (Monyer et al., 1994), although the identity of the NR2 subunit composition of AII NMDA receptors is unknown. Our data indicate that even in very well dark-adapted retina, NMDA receptors are still responsive to exogenous agonist, potentially due to the above reasons.

It is more straightforward to imagine the circumstances that would activate NMDA receptors on AII amacrine cells in vivo under scotopic conditions, when they are depolarized directly by glutamate released from rod bipolar cells onto postsynaptic AMPA receptors. Based on our results, we propose that ambient and/or spillover glutamate drives opening of nonsynaptic NMDA receptors on depolarized AII dendrites, thus linking modulation of Cx36-mediated coupling with the excitation of AII amacrine cells. Such a situation fits with the observed increase in AII-AII coupling adapted to scotopic background illumination (Bloomfield et al., 1997; Bloomfield and Völgyi, 2004), which will evoke glutamate release from some rod bipolar cells. Since rod photoreceptors diverge to two rod bipolar cells (Sterling et al., 1988), even single rod activations have the potential to activate multiple rod bipolar cell inputs onto a single AII, which might cause a local elevation in ambient glutamate and increase local AII-AII coupling, as proposed above. Coupling then increases further as increased background illumination more strongly stimulates a larger pool of rod bipolar cells. Our data from dark-adapted retina support this scenario, as pharmacological activation of ON- type bipolar cells and activation by a background light increment both drive increased phosphorylation of Cx36 gap junctions. Thus in our model nonsynaptic NMDA receptors on AIIs provide a link between local activity in rod bipolar cells and local coupling in the AII network, while synaptic AMPA receptors provide the depolarization to overcome the threshold for NMDA receptor activation.

The NMDA-driven increase in phosphorylation of Cx36 requires activation of CaMKII. This arrangement in AII amacrine cells bears some similarities with fish Mauthner cells, where Cx35 gap junctions are encircled by postsynaptic densities that contain synaptic NMDA receptors (Tuttle et al., 1986; Flores et al., 2010), and potentiation of electrical coupling also requires NMDA receptor and CaMKII activation (Pereda and Faber, 1996; Pereda et al., 1998). A similar physical organization of synaptic NMDA receptors with $\mathrm{Cx} 36$ gap junctions in mammalian inferior olive neurons that show highly variable coupling (Hoge et al., 2011) may presage a similar regulatory scheme. However, the AII amacrine cell also shows a distinct difference in that there do not appear to be excitatory chemical synapses directly associated with the NMDA/Cx36 complexes. This unique arrangement has led us to conclude that the primary purpose of NMDA receptors in AII amacrine cells is to drive increased coupling through Cx36 gap junctions.

A critical design feature of an efficient dynamic regulatory mechanism is to employ the opposing actions of two independent pathways to increase and decrease the amplitude of the regulated parameter. In the AII amacrine cell, the glutamatedriven increase in Cx36 phosphorylation and AII coupling is opposed by dopaminergic signaling via a D1-like receptor. The latter involves a cAMP/PKA signaling pathway that activates protein phosphatase $2 \mathrm{~A}$ and reduces coupling by reducing Cx36 phosphorylation (Kothmann et al., 2009). Retinal dopamine secretion is increased by bright light adaptation, and we have shown that it is sufficient to overwhelm the pathway favoring increased Cx36 phosphorylation (Kothmann et al., 2009). The presence of these independent, opposed signaling pathways allows for precise, dynamic control of coupling wherein the relative strength of each pathway is continuously compared with dictate the coupling state. This push-pull organization results in a nonlinear relationship between AII coupling and background illumination. Such an organization is likely a common theme in regulation of Cx36-mediated electrical coupling.

Cx36 displays a tremendous potential for regulation, which need not be limited to only two opposing pathways. Multiple kinases converge onto the regulatory residues of $\mathrm{Cx} 36$ (Ouyang et al., 2005; Patel et al., 2006; Urschel et al., 2006; Kothmann et al., 2007; Alev et al., 2008), and in all likelihood multiple phosphatases do as well. Furthermore, alternate signaling pathway organization can lead to distinct properties. This is exemplified by retinal photoreceptors in which a cAMP/PKA signaling pathway that lacks an intervening phosphatase drives increased photoreceptor coupling via increased Cx35 phosphorylation (Li et al., 2009), precisely the reverse of the cAMP signaling found in AIIs.

Electrical synapses are widespread in the CNS (Connors and Long, 2004), but plasticity has thus far been detected in a relatively small number of circuits. Noradrenergic modulation of coupling in hippocampal neurogliaform cells (Zsiros and Maccaferri, 2008) strongly resembles the dopaminergic modulation of AII amacrine cell coupling. Metabotropic glutamate receptors have also been found to drive uncoupling of interneurons in the thalamic reticular nucleus (Landisman and Connors, 2005). Such 
forms of plasticity are an intrinsic property of electrical synapses containing Cx36 and are likely widespread in the CNS.

Plasticity of electrical synapses imparts important emergent properties to the neural networks that employ them. While strong coupling promotes spike synchrony, weaker coupling can promote antiphase and phase-locked states (Marder, 1998; Saraga et al., 2006). The dynamic modulation of electrical synaptic strength can efficiently regulate these complex network properties. Disruption of higher-order processes such as memory of complex objects and motor learning in Cx36 knock-out animals (Frisch et al., 2005; Van Der Giessen et al., 2008) is likely a manifestation of the loss of this plasticity, as is impaired contextdependent fear learning when Cx36 gap junctions are blocked (Bissiere et al., 2011). As both NMDA receptors and Cx36 gap junctions are widely expressed throughout the vertebrate brain, it seems likely that nonsynaptic NMDA/Cx36 complexes may exist in other central neurons, where NMDA receptors could modulate electrical coupling as a function of local excitation history.

\section{References}

Alev C, Urschel S, Sonntag S, Zoidl G, Fort AG, Höher T, Matsubara M, Willecke K, Spray DC, Dermietzel R (2008) The neuronal connexin36 interacts with and is phosphorylated by CaMKII in a way similar to CaMKII interaction with glutamate receptors. Proc Natl Acad Sci U S A 105:20964-20969.

Arriza JL, Eliasof S, Kavanaugh MP, Amara SG (1997) Excitatory amino acid transporter 5 , a retinal glutamate transporter coupled to a chloride conductance. Proc Natl Acad Sci U S A 94:4155-4160.

Barbour B, Häusser M (1997) Intersynaptic diffusion of neurotransmitter. Trends Neurosci 20:377-384.

Bissiere S, Zelikowsky M, Ponnusamy R, Jacobs NS, Blair HT, Fanselow MS (2011) Electrical synapses control hippocampal contributions to fear learning and memory. Science 331:87-91.

Bloomfield SA, Völgyi B (2004) Function and plasticity of homologous coupling between AII amacrine cells. Vision Res 44:3297-3306.

Bloomfield SA, Xin D, Osborne T (1997) Light-induced modulation of coupling between AII amacrine cells in the rabbit retina. Vis Neurosci 14:565-576.

Chávez AE, Diamond JS (2008) Diverse mechanisms underlie glycinergic feedback transmission onto rod bipolar cells in rat retina. J Neurosci 28:7919-7928.

Colbran RJ (2004) Targeting of calcium/calmodulin-dependent protein kinase II. Biochem J 378:1-16.

Colbran RJ, Brown AM (2004) Calcium/calmodulin-dependent protein kinase II and synaptic plasticity. Curr Opin Neurobiol 14:318-327.

Connors BW, Long MA (2004) Electrical synapses in the mammalian brain. Annu Rev Neurosci 27:393-418.

Cull-Candy S, Brickley S, Farrant M (2001) NMDA receptor subunits: diversity, development and disease. Curr Opin Neurobiol 11:327-335.

Deans MR, Volgyi B, Goodenough DA, Bloomfield SA, Paul DL (2002) Connexin36 is essential for transmission of rod-mediated visual signals in the mammalian retina. Neuron 36:703-712.

Dunn FA, Doan T, Sampath AP, Rieke F (2006) Controlling the gain of rod-mediated signals in the Mammalian retina. J Neurosci 26:3959-3970.

Famiglietti EV Jr, Kolb H (1975) A bistratified amacrine cell and synaptic circuitry in the inner plexiform layer of the retina. Brain Res 84:293-300.

Feigenspan A, Teubner B, Willecke K, Weiler R (2001) Expression of neuronal connexin36 in AII amacrine cells of the mammalian retina. J Neurosci 21:230-239.

Flores CE, Cachope R, Nannapaneni S, Ene S, Nairn AC, Pereda AE (2010) Variability of distribution of $\mathrm{Ca}(2+) / \mathrm{calmodulin}$-dependent kinase II at mixed synapses on the Mauthner cell: colocalization and association with connexin 35. J Neurosci 30:9488-9499.

Frisch C, De Souza-Silva MA, Söhl G, Güldenagel M, Willecke K, Huston JP, Dere E (2005) Stimulus complexity dependent memory impairment and changes in motor performance after deletion of the neuronal gap junction protein connexin36 in mice. Behav Brain Res 157:177-185.

Gottesman J, Miller RF (2003) N-methyl-D-aspartate receptors contribute to the baseline noise of retinal ganglion cells. Vis Neurosci 20:329-333.

Güldenagel M, Ammermüller J, Feigenspan A, Teubner B, Degen J, Söhl G,
Willecke K, Weiler R (2001) Visual transmission deficits in mice with targeted disruption of the gap junction gene connexin36. J Neurosci 21:6036-6044.

Habermann CJ, O’Brien BJ, Wässle H, Protti DA (2003) AII amacrine cells express L-type calcium channels at their output synapses. J Neurosci 23:6904-6913.

Hampson EC, Vaney DI, Weiler R (1992) Dopaminergic modulation of gap junction permeability between amacrine cells in mammalian retina. J Neurosci 12:4911-4922.

Hartveit E, Veruki ML (1997) AII amacrine cells express functional NMDA receptors. Neuroreport 8:1219-1223.

Hoge GJ, Davidson KG, Yasumura T, Castillo PE, Rash JE, Pereda AE (2011) The extent and strength of electrical coupling between inferior olivary neurons is heterogeneous. J Neurophysiol 105:1089-1101.

Jahr CE, Stevens CF (1990) Voltage dependence of NMDA-activated macroscopic conductances predicted by single-channel kinetics. J Neurosci 10:3178-3182.

Kolb H, Famiglietti EV (1974) Rod and cone pathways in the inner plexiform layer of cat retina. Science 186:47-49.

Kothmann WW, Li X, Burr GS, O’Brien J (2007) Connexin 35/36 is phosphorylated at regulatory sites in the retina. Vis Neurosci 24:363-375.

Kothmann WW, Massey SC, O'Brien J (2009) Dopamine-stimulated dephosphorylation of connexin 36 mediates AII amacrine cell uncoupling. J Neurosci 29:14903-14911.

Landisman CE, Connors BW (2005) Long-term modulation of electrical synapses in the mammalian thalamus. Science 310:1809-1813.

Li H, Chuang AZ, O'Brien J (2009) Photoreceptor coupling is controlled by connexin 35 phosphorylation in zebrafish retina. J Neurosci 29:15178-15186.

Li W, Trexler EB, Massey SC (2002) Glutamate receptors at rod bipolar ribbon synapses in the rabbit retina. J Comp Neurol 448:230-248.

Marder E (1998) Electrical synapses: beyond speed and synchrony to computation. Curr Biol 8:R795-R797.

Massey SC, Mills SL (1999) Antibody to calretinin stains AII amacrine cells in the rabbit retina: double-label and confocal analyses. J Comp Neurol 411:3-18.

Mills SL, O’Brien JJ, Li W, O’Brien J, Massey SC (2001) Rod pathways in the mammalian retina use connexin 36. J Comp Neurol 436:336-350.

Mills SL, Xia XB, Hoshi H, Firth SI, Rice ME, Frishman LJ, Marshak DW (2007) Dopaminergic modulation of tracer coupling in a ganglionamacrine cell network. Vis Neurosci 24:593-608.

Monyer H, Burnashev N, Laurie DJ, Sakmann B, Seeburg PH (1994) Developmental and regional expression in the rat brain and functional properties of four NMDA receptors. Neuron 12:529-540.

Mørkve SH, Veruki ML, Hartveit E (2002) Functional characteristics of non-NMDA-type ionotropic glutamate receptor channels in AII amacrine cells in rat retina. J Physiol 542:147-165.

Olverman HJ, Jones AW, Watkins JC (1984) L-glutamate has higher affinity than other amino acids for $\left[{ }^{3} \mathrm{H}\right]$-D-AP5 binding sites in rat brain membranes. Nature 307:460-462.

Ouyang X, Winbow VM, Patel LS, Burr GS, Mitchell CK, O’Brien J (2005) Protein kinase A mediates regulation of gap junctions containing connexin35 through a complex pathway. Brain Res Mol Brain Res 135:1-11.

Patel LS, Mitchell CK, Dubinsky WP, O’Brien J (2006) Regulation of gap junction coupling through the neuronal connexin Cx35 by nitric oxide and cGMP. Cell Commun Adhes 13:41-54.

Pereda AE, Faber DS (1996) Activity-dependent short-term enhancement of intercellular coupling. J Neurosci 16:983-992.

Pereda AE, Bell TD, Chang BH, Czernik AJ, Nairn AC, Soderling TR, Faber DS (1998) $\mathrm{Ca}^{2+} /$ calmodulin-dependent kinase II mediates simultaneous enhancement of gap-junctional conductance and glutamatergic transmission. Proc Natl Acad Sci U S A 95:13272-13277.

Pereda A, O’Brien J, Nagy JI, Bukauskas F, Davidson KG, Kamasawa N, Yasumura T, Rash JE (2003) Connexin 35 mediates electrical transmission at mixed synapses on Mauthner cells. J Neurosci 23:7489-7503.

Pow DV, Barnett NL (2000) Developmental expression of excitatory amino acid transporter 5: a photoreceptor and bipolar cell glutamate transporter in rat retina. Neurosci Lett 280:21-24.

Rieke F, Rudd ME (2009) The challenges natural images pose for visual adaptation. Neuron 64:605-616.

Rodieck RW (1998) The first steps in seeing. Sunderland, MA: Sinauer. Sah P, Hestrin S, Nicoll RA (1989) Tonic activation of NMDA receptors by 
ambient glutamate enhances excitability of neurons. Science 246:815-818.

Saraga F, Ng L, Skinner FK (2006) Distal gap junctions and active dendrites can tune network dynamics. J Neurophysiol 95:1669-1682.

Singer JH, Diamond JS (2003) Sustained $\mathrm{Ca}^{2+}$ entry elicits transient postsynaptic currents at a retinal ribbon synapse. J Neurosci 23:10923-10933.

Sterling P, Freed MA, Smith RG (1988) Architecture of rod and cone circuits to the on-beta ganglion cell. J Neurosci 8:623-642.

Strettoi E, Raviola E, Dacheux RF (1992) Synaptic connections of the narrow-field, bistratified rod amacrine cell (AII) in the rabbit retina. J Comp Neurol 325:152-168.

Trexler EB, Li W, Massey SC (2005) Simultaneous contribution of two rod pathways to AII amacrine and cone bipolar cell light responses. J Neurophysiol 93:1476-1485.

Tuttle R, Masuko S, Nakajima Y (1986) Freeze-fracture study of the large myelinated club ending synapse on the goldfish Mauthner cell: special reference to the quantitative analysis of gap junctions. J Comp Neurol 246:202-211.

Urschel S, Höher T, Schubert T, Alev C, Söhl G, Wörsdörfer P, Asahara T, Dermietzel R, Weiler R, Willecke K (2006) Protein kinase A-mediated phosphorylation of connexin 36 in mouse retina results in decreased gap junctional communication between AII amacrine cells. J Biol Chem 281:33163-33171.

Van Der Giessen RS, Koekkoek SK, van Dorp S, De Gruijl JR, Cupido A, Khosrovani S, Dortland B, Wellershaus K, Degen J, Deuchars J, Fuchs EC, Monyer H, Willecke K, De Jeu MT, De Zeeuw CI (2008) Role of olivary electrical coupling in cerebellar motor learning. Neuron 58:599-612.

Vaney DI (1991) Many diverse types of retinal neurons show tracer coupling when injected with biocytin or Neurobiotin. Neurosci Lett 125:187-190.

Vardi N, Smith RG (1996) The AII amacrine network: coupling can increase correlated activity. Vision Res 36:3743-3757.

Veruki ML, Hartveit E (2002) AII (Rod) amacrine cells form a network of electrically coupled interneurons in the mammalian retina. Neuron 33:935-946.

Veruki ML, Mørkve SH, Hartveit E (2003) Functional properties of spontaneous EPSCs and non-NMDA receptors in rod amacrine (AII) cells in the rat retina. J Physiol 549:759-774.

Veruki ML, Mørkve SH, Hartveit E (2006) Activation of a presynaptic glutamate transporter regulates synaptic transmission through electrical signaling. Nat Neurosci 9:1388-1396.

Völgyi B, Deans MR, Paul DL, Bloomfield SA (2004) Convergence and segregation of the multiple rod pathways in mammalian retina. J Neurosci 24:11182-11192.

Wayman GA, Lee YS, Tokumitsu H, Silva AJ, Soderling TR (2008) Calmodulin-kinases: modulators of neuronal development and plasticity. Neuron 59:914-931.

Witkovsky P (2004) Dopamine and retinal function. Doc Ophthalmol 108:17-40.

Xia XB, Mills SL (2004) Gap junctional regulatory mechanisms in the AII amacrine cell of the rabbit retina. Vis Neurosci 21:791-805.

Xin D, Bloomfield SA (1999) Dark- and light-induced changes in coupling between horizontal cells in mammalian retina. J Comp Neurol 405:75-87.

Yang XD, Korn H, Faber DS (1990) Long-term potentiation of electrotonic coupling at mixed synapses. Nature 348:542-545.

Zhang J, Diamond JS (2006) Distinct perisynaptic and synaptic localization of NMDA and AMPA receptors on ganglion cells in rat retina. J Comp Neurol 498:810-820.

Zhou C, Dacheux RF (2004) All amacrine cells in the rabbit retina possess AMPA-, NMDA-, GABA-, and glycine-activated currents. Vis Neurosci 21:181-188.

Zsiros V, Maccaferri G (2008) Noradrenergic modulation of electrical coupling in GABAergic networks of the hippocampus. J Neurosci 28:18041815. 